\title{
On the disequilibrium response and climate change vulnerability of the mass-balance glaciers in the Alps
}

\section{Article}

Cite this article: Carturan L, Rastner P, Paul F (2020). On the disequilibrium response and climate change vulnerability of the massbalance glaciers in the Alps. Journal of Glaciology 66(260), 1034-1050. https://doi.org/ 10.1017/jog.2020.71

Received: 21 December 2019

Revised: 28 July 2020

Accepted: 31 July 2020

First published online: 9 September 2020

\section{Key words:}

climate change; glacier mass balance; glacier monitoring; mountain glaciers

\section{Author for correspondence:}

Luca Carturan, E-mail: luca.carturan@unipd.it
Luca Carturan $^{1,2}$, Philipp Rastner ${ }^{3}$ and Frank Paul ${ }^{3}$

${ }^{1}$ Department of Land, Environment, Agriculture and Forestry, University of Padova, Viale dell'Università 16, 35020, Legnaro, Padova, Italy; ${ }^{2}$ Department of Geosciences, University of Padova, Via Gradenigo 6, 35131, Padova, Italy and ${ }^{3}$ Department of Geography, University of Zurich, Winterthurerstr. 190, 8057 Zurich, Switzerland

\begin{abstract}
Glaciers in the Alps and several other regions in the world have experienced strong negative mass balances over the past few decades. Some of them are disappearing, undergoing exceptionally negative mass balances that impact the mean regional value, and require replacement. In this study, we analyse the geomorphometric characteristics of 46 mass-balance glaciers in the Alps and the long-term mass-balance time series for a subset of nine reference glaciers. We identify regime shifts in the mass-balance time series (when non-climatic controls started impacting) and develop a glacier vulnerability index (GVI) as a proxy for their possible future development, based on criteria such as hypsometric index, breaks in slope, thickness distribution and elevation change pattern. We found that the subset of 46 mass-balance glaciers reflects the characteristics of the total glacier sample very well and identified a region-specific variability of the mass balance. As the GVI is strongly related to cumulative glacier mass balances, it can be used as a pre-selector of future mass-balance glaciers. We conclude that measurements on rapidly shrinking glaciers should be continued as long as possible to identify regime shifts in hind-cast and better understand the impacts of climatic variability on such glaciers.
\end{abstract}

\section{Introduction}

Glacier changes are widely recognised as key indicators of climate change (e.g. Vaughan and others, 2013), meaning that they respond very sensitively to small changes in climatic conditions. In particular, the dramatic retreat of glaciers in nearly all regions of the world over the past century has demonstrated the impacts of atmospheric warming for a large public (Zemp and others, 2015; Rastner and others, 2016). Mass-balance measurements are more challenging to perform compared to length-change measurements, but easier to interpret as they represent a direct and undelayed response to the atmospheric forcing. Thereby, long-term time series of glacier mass balance serve several purposes, for example: (1) detection of climate trends, (2) spatio-temporal extrapolation of their contribution to sea-level (Marzeion and others, 2012; Gardner and others, 2013; Giesen and Oerlemans, 2013; Radić and others, 2014; Huss and Hock, 2015), (3) determination of their contribution to run-off and regional hydrology (Casassa and others, 2009; Kaser and others, 2010; Huss, 2011; Carturan and others, 2019), (4) calibration and validation of numerical models (e.g. Huss and Farinotti, 2012) and (5) calculation of crustal uplift (Barletta and others, 2006; Dietrich and others, 2010), among others.

For all of the above applications, the most severe issue is the disappearance of a reference glacier (Cogley and others, 2011) with a long time series, when climatic conditions are no longer suitable for its survival. Unfortunately, this is not only a problem in the Alps (e.g. Carturan and others, 2013a; Thibert and others, 2013), but is occurring in several other regions of the world with strong glacier decline (e.g. Ramirez and others, 2001; Mölg and others, 2017; Prinz and others, 2018). The disappearance of mass-balance glaciers with a longterm record has already been recognised in earlier studies (e.g. Haeberli and others, 2007, 2013) as a serious issue for the continuation of long-term glacier monitoring strategies. In regions with sparse measurements this loss is particular unfortunate, as it considerably increases the uncertainty of the related regional-scale estimates of annual glacier mass loss (e.g. Zemp and others, 2019).

As the value of a mass-balance time series increases with its length, the loss of such time series is regrettable. It increases the uncertainty of any regional scale extrapolation up to a point where it is no longer possible (e.g. in regions with only a few measured glaciers). At best, a nearby glacier is found in time as a replacement to have parallel measurements over a sufficient period (Carturan, 2016; Galos and others, 2017). However, as there is a high glacier-to-glacier variability in mass-balance time series (e.g. Kuhn, 1985), the new glacier might have different characteristics, altering the regionally averaged mass-balance time series. Apart from missing mass-balance data, the loss of glaciers in general might have other severe impacts on human well-being, for example in regions depending on glacier meltwater, be it for agriculture, run-off regulation or hydropower production (e.g. Vergara and others, 2007; Sorg and others, 2012; Lutz and others, 2016), for tourism or as a source of natural hazards once 
bare rock and unconsolidated debris are exposed (e.g. Ritter and others, 2012; Huggel and others, 2015; Mark and Fernández, 2017; Zanoner and others, 2017). Unfortunately, we have also limited countable evidence on the glaciers that have disappeared since a certain point in time, which resulted in an underestimation of their contribution to sea-level rise (Parkes and Marzeion, 2018). Thereby, defining when a glacier has actually disappeared is a challenge (Leigh and others, 2019).

Long before a glacier disappears due to climate change, reinforcement feedbacks might start to interfere and create a more negative mass balance than expected from climatic change alone, i.e. causing a disequilibrium response (Pelto, 2010). In particular, down-wasting with disintegration into several smaller glacier parts has a very negative impact on mass balance as glacier tongues are separated from the accumulation area, and thermal radiation from rock outcrops, combined with decreased cooling effects over smaller glaciers, can enhance melt considerably (e.g. Greuell and Böhm, 1998; Greuell and others, 1997; Carturan and others, 2015). A key question is thus if the disequilibrium response of a glacier can be identified in its mass-balance time series, so that the glacier can be removed from regionally averaged mass-balance values in retrospect. Despite intense use of massbalance time series for numerous applications (see above), this aspect has so far not been analysed and considered. Accordingly, calculations using these time series as an input (e.g. for model calibration) might be biased and generate wrong results. A first aim of this study is thus to identify related shifts in the mass-balance regime of glaciers in the Alps with long-term observations.

A second aim of this study is to characterise the larger sample of glaciers with mass-balance measurements (I) topographically (e.g. hypsometry, breaks in slope, aspect and elevation range) and (II) by a set of further criteria related to their overall health and vulnerability. Health criteria include (a) a continued negative mass balance despite strong shrinkage (requires area change analyses), (b) a potential disequilibrium response with mass loss in the accumulation area (requires elevation change analyses), (c) the size of the accumulation area at the end of the ablation season (requires analysis of satellite image time series) and (d) flow velocities close to zero (Stocker-Waldhuber and others, 2019) combined with collapse of subglacial cavities (requires space-borne and field observations). By investigating these factors, this analysis should reveal the vulnerability of the currently measured glaciers in the Alps in view of the anticipated further temperature increase (Kotlarski and others, 2014), and provide useful criteria for replacing disappearing glaciers with long-term mass-balance series in good time.

In this study, we have investigated topic (I) and points (a) to (c) of topic (II) for 46 glaciers with mass-balance measurements in the Alps. We have used time series of satellite imagery to determine area changes and snowline variability, as well as digital elevation models (DEMs) from two points in time to determine the elevation change patterns among the glaciers. For a smaller sample of nine glaciers with long-term mass-balance records, we have analysed in detail each time series in comparison with the others (to analyse regional variability and find the regime shifts) along with the analysis of their vulnerability to determine possible reasons for their disequilibrium response. Ultimately, we applied the vulnerability index to all measured glaciers in the Alps indicating which of them might be impacted next by non-climatic effects on their mass balance.

\section{Study region}

The European Alps (called 'Alps' hereafter) are an arc-shaped mountain range that is $\sim 1500 \mathrm{~km}$ long, stretches from $2^{\circ}$ to $18^{\circ} \mathrm{E}$ and $43^{\circ}$ to $49^{\circ} \mathrm{N}$, and is subdivided by the administrative boundaries of nine different countries (Austria, Croatia, France, Germany, Italy, Liechtenstein, Monaco, Slovenia and Switzerland). Its elevation averages $\sim 2500 \mathrm{~m}$ a.s.l., peaking at Monte Bianco/Mont Blanc with $4810 \mathrm{~m}$ a.s.l. (Fig. 1). The Alps are affected by air masses of very different origins: mild and moist maritime air from the west, cool or cold polar air from north, dry and warm (in summer) or cold (in winter) continental air from east and warm African or Mediterranean air (sometimes very wet) from south. As the Alps constitute an important obstacle to the transit of moist air masses, they give rise to high horizontal and vertical gradients in precipitation. Annual precipitation amounts range from $\sim 400-500 \mathrm{~mm}$ at valley floors in the drier inner regions to $3000-3500 \mathrm{~mm}$ in the wettest areas (e.g. Jungfrau and Julian Prealps) (Isotta and others, 2014). Accordingly, there is a strong gradient in glacier mean elevation from the wetter outer regions at $\sim 2600 \mathrm{~m}$ a.s.l. to the drier interior at $\sim 3200 \mathrm{~m}$ a.s.l. (Paul and others, 2011). Climatic conditions range from slightly maritime to slightly continental and many glaciers are not strictly temperate but rather polythermal, with probably cold surface layers in the ablation area (Haeberli and Hoelzle, 1995), or with cold firn and ice at high altitudes (Suter and others, 2001). Whereas there is no significant trend in precipitation amounts over the past 150 years, temperatures increased $\sim 1^{\circ} \mathrm{C}$ between 1850 and 1980, and have increased an additional degree since 1980 (Auer and others, 2007).

In $2015 / 16$, there were 4394 glaciers larger $0.01 \mathrm{~km}^{2}$ in the Alps with different types (valley, mountain, hanging, cirque and plateau), covering a total area of $1806 \mathrm{~km}^{2}$ (Paul and others, 2020). The region is dominated by small glaciers ( $92 \%$ are $<1 \mathrm{~km}^{2}$ covering $28 \%$ of the area). However, the 21 largest glaciers $\left(>10 \mathrm{~km}^{2}\right)$ contribute only $0.5 \%$ to the total number of glaciers but cover about the same area (26\% of the total). Regular measurements of changes in glacier length (or terminus position) have been performed in the Alps since 1894 (Forel, 1895), starting with 85 glaciers and now being at 270 . They provide the backbone of our knowledge about glacier fluctuations in the Alps (e.g. Holzhauser and others, 2005; Zemp and others, 2015) and have been widely used for numerical modelling of past climate variability (e.g. Oerlemans, 2005; Goosse and others, 2018), as well as numerous other applications in hydrology and climate change research.

The first mass-balance measurements in the Alps were carried out on Rhône Glacier in the period from 1884 to 1909 , using the glaciological method (Huss and others, 2015). This method is based on the spatial extrapolation of thickness changes measured at least annually (at the end of the hydrological year) at stakes and snow pits using the glacier hypsometry. These are converted to water equivalent (w.e.) by multiplication with the density of ice and field-based measurements of snow and firn densities (Kaser and others, 2003). The longest continuous series of mass-balance measurements for an entire glacier date back to 1948 (Sarennes). The sample was extended in the following decades and is now at 46 glaciers per year.

Continuous series longer than 30 years currently exist for 40 glaciers worldwide and 11 in the Alps. Time series of massbalance values for glaciers in Switzerland show a large variability of the cumulative mass balance from glacier to glacier, but also some common trends: clear mass gains before the 1920s and 1980s, and fast mass loss in the 1940s and since about 1985 (Huss and others, 2015). It is assumed that the latter is related to a switch in the global climate regime (Reid and others, 2016). The current mean specific mass loss of $\sim 1 \mathrm{~m}$ w.e. $\mathrm{a}^{-1}$ multiplied with a glacier area of $\sim 2000 \mathrm{~km}^{2}$ (Paul and others, 2011) gives an average mass loss of $2 \mathrm{Gt} \mathrm{a}^{-1}$ for the Alps. 
Fig. 1. Geographic location of the mass-balance glaciers in the European Alps that have been analysed in this study.

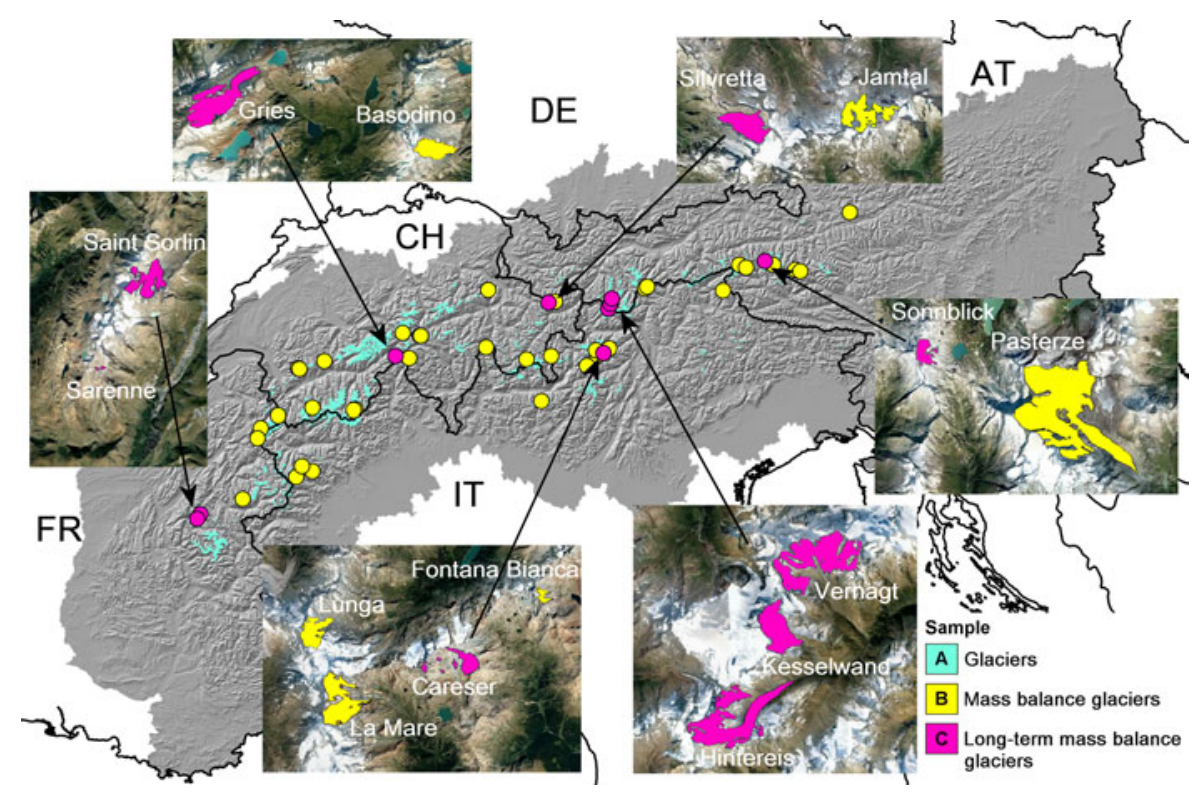

Assuming a residual ice volume of $\sim 70-100 \mathrm{~km}^{3}$ in the Alps in 2018 (Haeberli and others, 2019), complete glacier loss might be expected in 50 years at current rates of depletion.

\section{Data sets}

To ease calculations and comparisons across glaciers, we distinguish the three samples marked in Figure 1, namely Sample A: all glaciers, Sample B: 46 glaciers with mass-balance measurements between 2004 and 2013 and Sample C: nine glaciers with continuous long-term measurements since 1967. Sample B is included in Sample A and Sample C is included in both samples $\mathrm{A}$ and $\mathrm{B}$.

\subsection{Glacier outlines (01 and 02)}

Glacier outlines from 2003 (Paul and others, 2011) and 2006 (Salvatore and others, 2015) have been used as starting conditions for all glaciers. This dataset (O1 in the following) represents Sample A. To determine area changes for Sample B, a second dataset of glacier outlines (O2) was created using Landsat 7 and 8 scenes of the years 2013 and 2015. These new outlines were obtained by automatic classification of clean ice using the band ratio method and manual post-processing (e.g. to correct unclassified debris-covered glaciers) following Paul and others (2009).

\subsection{DEMs (D1, D2 and D3)}

Three different DEMs have been used for calculating topographic parameters and elevation changes. Topographic parameters for samples A and B were extracted from the $30 \mathrm{~m}$ ASTER GDEM2 (D1) that is a merged product using ASTER scenes acquired between 2000 and 2012. Although this DEM has local quality issues, it has no data voids and was available also for the very small glaciers in the sample. Glacier elevation changes were calculated by differencing the $1 \operatorname{arcsec}(\sim 30 \mathrm{~m})$ SRTM DEM acquired in 2000 (D2) from the 1 arcsec TanDEM-X DEM acquired about 2012-14 (D3) for the entire Alps. We have not corrected data voids or issues related to radar penetration as we were mostly interested in the pattern of the changes rather than correct absolute values. However, to be aware of the possible issues related to these DEMs, we have compared the elevation changes from SRTM and TanDEM-X with changes derived from two highaccuracy LiDAR DEMs with a cell size of $0.5 \mathrm{~m}$ obtained by surveys in 2003 and 2013 and commissioned by the University of Padova. This comparison was restricted to La Mare and Careser glaciers in the Ortles-Cevedale Group in Italy.

\subsection{Ice thickness distribution}

We used the distributed ice thickness dataset by Huss and Farinotti (2012) for calculation of an ice thickness index (ITI). The dataset provides physically-based ice thickness estimates for individual glaciers and is based on glacier outlines from 2003 (O1) to spatially constrain the modelling and the SRTM DEM (D2) for topographic information (e.g. surface slope and hypsometry).

\subsection{Mass-balance data}

Mass-balance data are collected in the field and distributed by the World Glacier Monitoring Service (WGMS). Apart from mean annual values, we also extracted values of the accumulation area ratio (AAR) and equilibrium line altitude (ELA) for the 46 glaciers of Sample B (including the nine from Sample C). The period from 2004 to 2013 was selected on the basis of available data to characterise their recent status and variations. All glaciers of Sample B are used for correlation and vulnerability analyses, whereas the mass-balance time series of glaciers in Sample C are analysed in more detail. The analysed glaciers in Samples B and $\mathrm{C}$ are rather well distributed over the glacierised regions of the Alps (Fig. 1). Twelve of them are located in Austria, 14 in Italy, 14 in Switzerland and six in France (Table S1).

\subsection{Satellite data}

Apart from the selected satellite scenes used to create the recent glacier outlines $(\mathrm{O} 2)$ for Sample B, we also used the time series of Landsat 5, 7 and 8 to derive snow cover maps over the 2004-2013 period for the 46 glaciers of Sample B, following Rastner and others (2019). From the maps showing minimum snow extent within each year we calculated the snow cover fraction (SCF) and snowline altitude (SLA) based on the ASTER GDEM II for each glacier. As not all years had scenes close to the end of the ablation period, both SCF and SLA values are expected to be different from the AAR and ELA values measured at each glacier. This possible discrepancy is quantified and discussed in Section 6.3. 


\section{Methods}

In Figure 2 we present a schematic overview of the datasets used and calculations performed based on the three samples displayed in Figure 1. The topographic comparison between samples A and $B$ should reveal how similar or representative the glaciers with mass-balance measurements are compared to the entire sample of glaciers in topographic terms. For the 46 glaciers in Sample $\mathrm{B}$ we performed a detailed analysis of their morphometric characteristics as well as their area and elevation changes using the datasets described in Section 3. Afterwards, the observed variability in morphometric characteristics and geometric changes is reduced to four classes for selected criteria, indicating increasing vulnerability (see Section 4.2). Moreover, together with recent massbalance variability in the decade from 2004 to 2013, morphometric characteristics are compared in a correlation analysis to reveal major dependencies among them (see Supplementary material). Finally, we perform a spatio-temporal analysis of the massbalance variability of Sample C, and compare cumulative differences from the mean mass balance with an index that is derived as the sum of the individual vulnerabilities for all glaciers in Sample B (Section 4.2.1)

\subsection{Topographic statistics (Sample A vs B)}

For the comparison of samples A and B we calculated frequency distributions of several topographic parameters for both samples, using the outlines from 2003 and 2006 (O1) and the ASTER GDEMv2 (D1). The former provided glacier areas for deriving a size class distribution, and outlines combined with the DEM are used to derive histograms of elevation range, mean elevation, mean slope and aspect sector, using zone statistics.

\subsection{Morphometric characteristics and changes (Sample B)}

\subsubsection{Vulnerability index}

The vulnerability of each glacier of Sample B was calculated as an index that combines nine different vulnerability criteria (Table 1). The index, named glacier vulnerability index (GVI), expresses the possibility for a glacier to exist for a shorter or longer monitoring period in the future. It is conceived as a method to support evaluation of the suitability of different glaciers for future mass-balance monitoring programmes, rather than as a prognostic tool. Although the GVI includes criteria that account for favourable topographic conditions, its application is not recommended for glaciers that are too small (area $<0.5 \mathrm{~km}^{2}$ ), because their mass balance tends to decouple from atmospheric forcing.

The nine vulnerability criteria reflect the dominant processes that govern glacier response and geometric adjustment, and can be derived from readily available input data. This makes the classification potentially applicable to other unmeasured glaciers (e.g. glaciers that might replace them). A rating from 1 to 4 , expressing increased vulnerability, was assigned to each glacier based on the analysis of frequency distributions, indications from literature (e.g. Jiskoot and others, 2009 for the hypsometric index (HI)) and in the correlation among variables (see Tables 1,2 and S2). The chosen thresholds are specific for the glacier geometries of the Alps (e.g. for elevation change or range) and the range of changes observed. They would thus have to be adjusted inother regions. The proposed class assignments might include a large range of possible absolute values or even neglect them when the focus is on the pattern of the change (e.g. gradients in different parts of a glacier). In the latter case, they are almost unaffected by small changes in absolute values (e.g. due to DEM uncertainties, glacier extent change or radar penetration). Total sums of the rating for all criteria constitute the GVI of each glacier. As a starting point, we used integer classes only and have given equal weight to all criteria, but lumped a few of likely local importance and auto-correlated (e.g. shadow, debris cover and avalanche contribution) into a single index. Tests have shown that the different weighting of the indices has small impacts on the GVI ranking of a glacier, but the general position remains similar. With the nine criteria and the four classes we use here, GVI values can range from 9 to 36. In the following subsections we describe each criterion together with its calculation and the four classes.

\subsubsection{Area change index (criterion 1)}

Area changes result from the combination of elevation changes and ice thickness distribution. As such, they are indicative of past imbalance but also of possible future developments (Pelto, 2010). For example, a glacier that shows limited area changes only close to its terminus seems to be less vulnerable than a glacier that lost area along its entire perimeter and/or is disintegrating into several pieces (Paul and others, 2004). We have considered here area changes from 2003 to 2015, and separated them between the upper and lower parts of a glacier, according to the following area change index (ACI):

$$
\mathrm{ACI}=-\frac{0.55 \times A C_{\mathrm{u}}}{0.45 \times A C_{\mathrm{l}}} \times A C_{\mathrm{t}}
$$

where $A C_{\mathrm{u}}, A C_{\mathrm{l}}$ and $A C_{\mathrm{t}}$ are percent area changes in the upper $55 \%$, lower $45 \%$ and total $(100 \%)$ of the glacier, respectively. The partition was done considering that on a global average the AAR related to a balanced mass budget is $\sim 0.58$ (Dyurgerov and others, 2009). Large ACI values (>0.3) mean large overall area loss and/or significant contribution from the upper part of the glacier to the total loss of area (class 4), whereas low ACI values $(<0.05)$ indicate small total area loss and/or a small contribution from the upper glacier part, suggesting a lower vulnerability (class 1). Values in between have been assigned to classes 2 and 3 (cf. Table 1).

In Figure 3 the area changes for the nine mass-balance glaciers of Sample C are shown, clearly revealing the large variability in possible changes. They range from the disintegration of Careser and Sarennes (class 4) to comparably smaller changes limited to the ablation area of Kesselwand and Sonnblick (class 1).

\subsubsection{Elevation change pattern (criterion 2)}

Glaciers that show thinning up to their highest elevations on decadal timescales are likely to disappear (Pelto, 2010). In the southern Ötztal Alps, patterns of elevation change show a high degree of variability, even within this small region (Fig. 4). This includes the minor elevation loss of Kesselwand near the terminus (class 1 ), the more extended regions of loss in the ablation region at Hintereis and Vernagtferner (class 2), and surface lowering impacting the entire area at Hochjochferner (class 4).

We have analysed elevation changes between 2000 and 2013 in relation to the planimetric distance from the terminus, drawing manually a centre line for each glacier and then extracting the elevation change for each cell of the D3-D2 grid (Fig. 2), along the centre line. To compare glaciers of different lengths, we have normalised the distance from the terminus by dividing it by the total glacier length. The plots in Figure 5 show the four classes of elevation change patterns, which are defined by the magnitude of elevation changes in different parts of the glacier, their spatial variability and their elevation dependence (cf. Table 1): class 1 represents glaciers with low variability and little elevation change. This class includes only three glaciers, Adler and Timorion that have high mean elevations (3459 and $3306 \mathrm{~m}$, respectively), and 
Fig. 2. Schematic overview of the datasets used and methodological flow chart. The abbreviations (D1, D2, $\mathrm{D} 3, \mathrm{O} 1$ and $\mathrm{O2}$ ) are explained in the text; ' $\mathrm{mb}$ ' is mass balance, 'Sat' is Satellite.

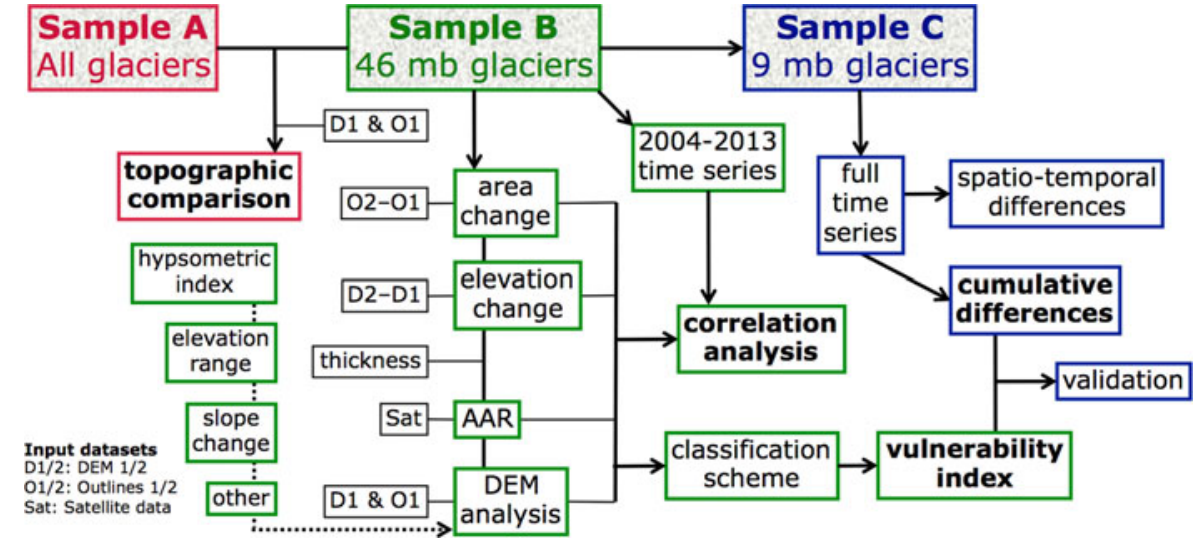

Table 1. Vulnerability criteria and ratings used for calculating the GVI for the 46 mass-balance glaciers of the European Alps. Outl. = Outline, Sat. = Satellite

\begin{tabular}{|c|c|c|c|c|c|c|c|}
\hline \multirow[b]{2}{*}{ No. } & \multirow[b]{2}{*}{ Vulnerability criterion } & \multirow[b]{2}{*}{ Input } & \multirow[b]{2}{*}{ Unit } & \multicolumn{4}{|c|}{ Vulnerability rating } \\
\hline & & & & 1 & 2 & 3 & 4 \\
\hline 1 & Area Change Index (ACI) & Outl. 1 and 2 & $\%$ & $<5$ & $5-15$ & $15-30$ & $>30$ \\
\hline 2 & Elevation change pattern & DEM 2 and 3 & $\mathrm{~m}$ & Mostly $<5$ & $<5$ upper half & 5-10 upper half & >10 entire glacier \\
\hline 3 & Ice Thickness Index (ITI) & Outl. 1, DEM 1 & None & $<0.9$ & $0.9-1.0$ & $1.0-1.1$ & $>1.1$ \\
\hline 4 & Slope changes & Slope (DEM 1) & Qualitative & Absent & One, small & One, large & Several, large \\
\hline 5 & Elevation range $^{a}$ & Outl. 1, DEM 1 & $\mathrm{~m}$ & $>900$ & $600-900$ & $300-600$ & $<300$ \\
\hline 6 & Hypsometric Index (HI) & Outl. 1, DEM 1 & None & $<-1.5$ & -1.5 to 0.0 & $0.0-1.5$ & $>1.5$ \\
\hline 7 & AAR sensitivity in the accumulation area & Outl. 1, DEM 1 & $100 \mathrm{~m}^{-1}$ & $<0.1$ & $0.1-0.3$ & $0.3-0.5$ & $>0.5$ \\
\hline 8 & $\overline{\mathrm{AAR}}$ & Sat. time series & None & $>0.5$ & $0.3-0.5$ & $0.1-0.3$ & $<0.1$ \\
\hline 9 & Avalanche, shadowing, debris cover & Outl. 1, DEM 1, Sat. & Qualitative & High & Medium & Low & Absent \\
\hline
\end{tabular}

${ }^{\text {a }}$ Elevation range is calculated excluding the $2^{\text {nd }}$ and $98^{\text {th }}$ percentiles in the hypsometric curve.

Kesselwand that has a large accumulation area above $3200 \mathrm{~m}$ (top-heavy).

Class 2 includes nine glaciers that show minor elevation changes in their upper half and large thinning in their lower half, with high elevation dependence. This behaviour is typical of glaciers in 'active retreat', which are shrinking almost exclusively at their lower margins but still preserve an accumulation area, i.e. with no elevation loss or even a small gain (e.g. Sonnblick and Vernagt).

Class 3 includes 20 glaciers showing higher imbalance, where thinning was larger and significant also in their upper half. They also showed shrinkage at higher elevations (e.g. Hintereis, Silvretta and Gries).

Class 4 represents 14 glaciers with the highest imbalance and strong thinning also at their highest elevations (e.g. Careser, Sarennes and Saint Sorlin). This resulted in a widespread contraction of glacier margins and progressive disintegration into smaller units and dead ice patches (disequilibrium response).

\subsubsection{Ice thickness distribution and longitudinal slope changes (criteria 3 and 4)}

Ice thickness is an indicator of both vulnerability and glacier response time. A related Ice Thickness Index (ITI) was calculated as the ratio between the normalised thickness (i.e. the local thickness divided by the maximum thickness) integrated along the lower and upper half of a centre line. This separation is based on the normalised distance from terminus (i.e. half of the glacier length), and does not consider glacier hypsometry. Top-heavy glaciers $(\mathrm{ITI}<1)$ have been considered less vulnerable than bottom-heavy glaciers (ITI $>1$ ) despite the observation that it might take considerable time until the ice in this zone melts. In Figure 6 we report four examples of normalised ice thickness vs normalised distance from the terminus, representing the four ITI classes.

Similarly, glaciers with an uneven or undulating glacier bed are more prone to disintegration when getting thinner and are thus more vulnerable than glaciers with a more constantly flat or steep bedrock profile (Fig. 7a). We have manually classified glaciers as highly vulnerable if they have one or more large breaks in slope, and less vulnerable if slope changes are minor or absent (Table 1). Slope changes were assessed qualitatively from 2-D elevation profiles extracted along the centre lines from the D1 DEM.

\subsubsection{Elevation range and hypsometric index (criteria 5 and 6)}

The elevation range of a glacier affects its ability to maintain an accumulation area during years with strong melting. If the range is too small, all snow (and later also firn) might melt away up to the highest elevations, resulting in a surface lowering and strong reduction of albedo, both further enhancing meltdown. Considering the histogram of elevation range values, we have used steps of $300 \mathrm{~m}$ to assign vulnerability classes 1 to 4 (Table 1).

The hypsometric distribution of area vs altitude is well recognised as an important control of glacier response to climatic changes because, in combination with a mass-balance gradient, it regulates the imbalance between net accumulation and ablation in response to ELA fluctuations (Furbish and Andrews, 1984). We calculated a Hypsometric Index (HI) according to Jiskoot and others (2009), with HI values lower than -1.5 indicating 'top-heavy' glaciers, with a large fraction of their area at high elevation and lower vulnerability (class 1 ) compared to the 'bottomheavy' glaciers, with $\mathrm{HI}>1.5$ and most of their area lying at low elevation (class 4). Classes 2 and 3 have been assigned to values in-between (Table 1). Note that HI refers only to glacier area and elevation whereas ITI refers to ice thickness. 

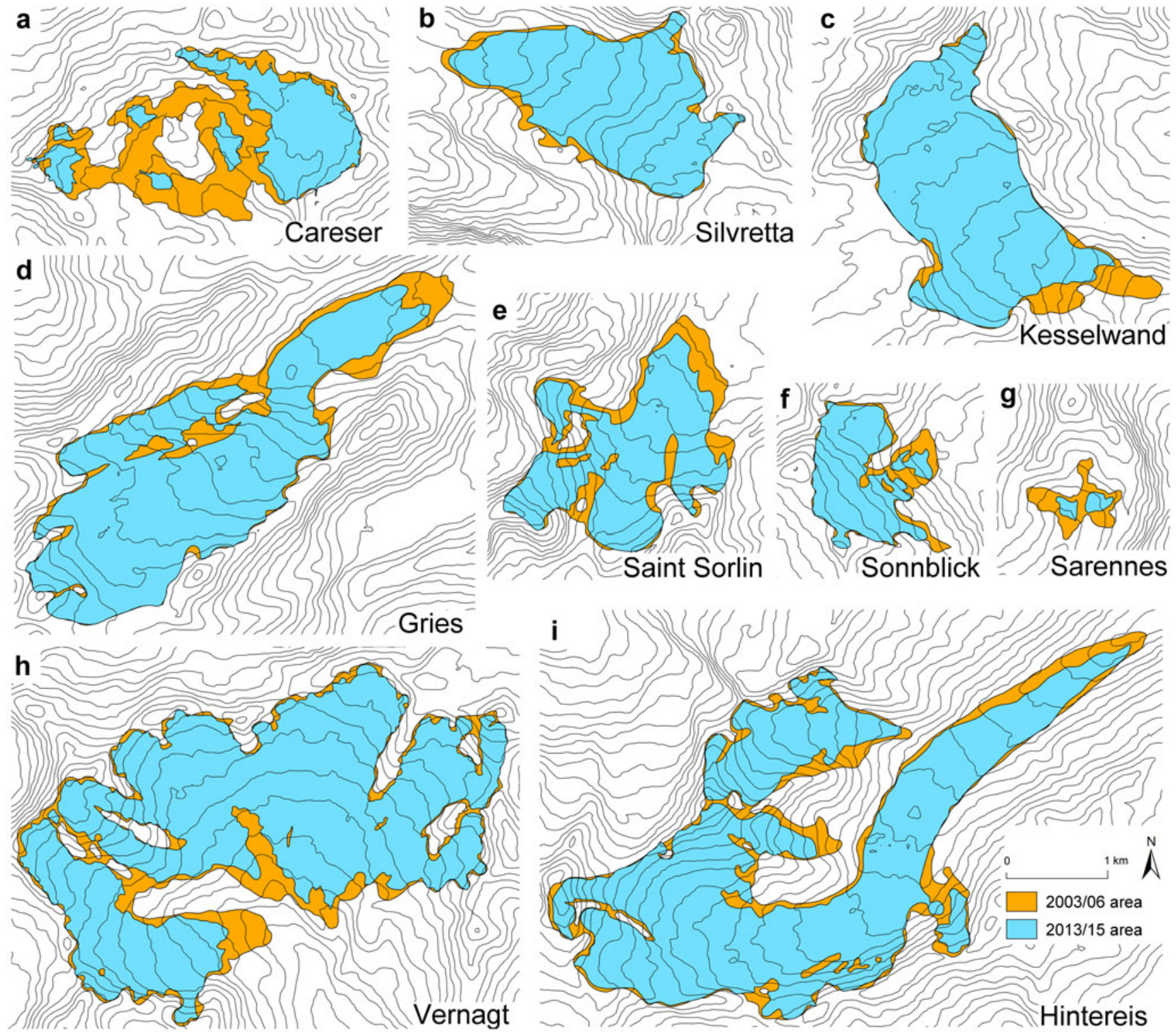

Fig. 3. Area change of glaciers with continuous long-term measurements (Sample C) from 2003/06 to 2013/15.

4.2.6 AAR sensitivity and observed AAR values (criteria 7 and 8) The AAR sensitivity in the accumulation area is derived from the hypsometric curve, and expresses the change in the size of the accumulation area in response to a unit change in ELA. This variable accounts for the shape of the upper part of the glacier (flat or steep) and its effects in the preservation of an accumulation area following a possible ELA rise. Resulting values range from 0 to 1 that are assigned to classes 1 to 4 according to Table 1 . A similar approach was used by Paul and others (2007) to model future glacier extents from a prescribed shift of the ELA and specific balanced-budget AAR values.

Because the AAR is strongly related to the annual mass balance of a glacier, average AAR values observed over a sufficiently long time period indicate the vulnerability of a glacier, assuming unchanged atmospheric conditions. Unlike variables derived from glacier geometry, the AAR enables accounting for regional climatic factors. For example, glaciers receiving high amounts of snowfall might benefit from a larger remaining snow cover despite their less favourable elevation range. The mean 2004-2013 AAR $(\overline{\mathrm{AAR}})$ was used for classifying glaciers from highly vulnerable $(\overline{\mathrm{AAR}}<0.1)$ to resilient $(\overline{\mathrm{AAR}}>0.5)$. In the case AAR values have not been reported for individual glaciers of Sample B (for
Sample C they are complete), we have used the satellite-derived SCF as a proxy for the AAR (Fig. 8).

\subsubsection{Avalanche, shadowing and debris cover (criterion 9)}

Glaciers located under topographically favourable conditions may benefit from increased snow accumulation by avalanches and decreased ablation due to terrain shadowing. These are generally small glaciers lying at the bottom of steep rock walls in high-relief areas, which during deglaciation tend to persist and decouple from regional temperature fluctuations (e.g. Kuhn, 1995; DeBeer and Sharp, 2009; Grünewald and Scheithauer, 2010; Carturan and others, 2013b). Additionally, debris cover reduces surface melt (e.g. Evatt and others, 2015; Rounce and others, 2018) and thus reduces the vulnerability of glaciers with low-lying tongues or a small elevation range. We have grouped all three processes into one index because they tend to occur jointly and exhibit a similar forcing on mass balance, defining four classes of vulnerability that have been assessed qualitatively. Low vulnerability (class 1) is assigned to glaciers that are strongly shaded, covered by debris in their ablation area and mostly fed by avalanches (see e.g. the Montasio Glacier in Fig. 7b); high vulnerability (class 4) is inferred where these processes are absent and 


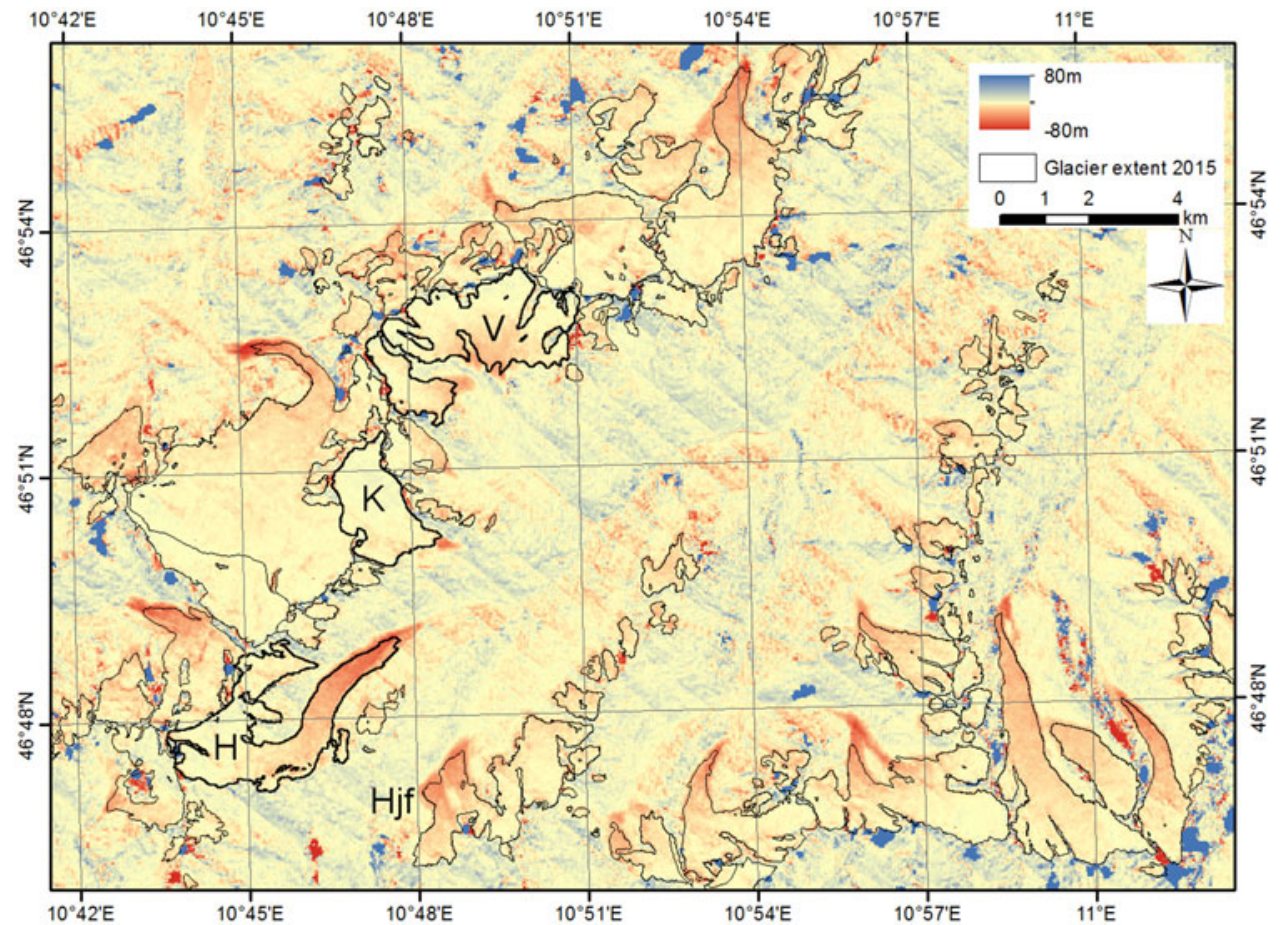

Fig. 4. Elevation change calculated between the SRTM DEM and TanDEM-X DEM in the Ötztal region (Austrian Alps). Three mass-balance glaciers are highlighted with thicker outlines ( $\mathrm{H}=$ Hintereis, $\mathrm{K}=$ Kesselwand, $\mathrm{V}=$ Vernagt), $\mathrm{Hjf}$ is Hochjoch Ferner.

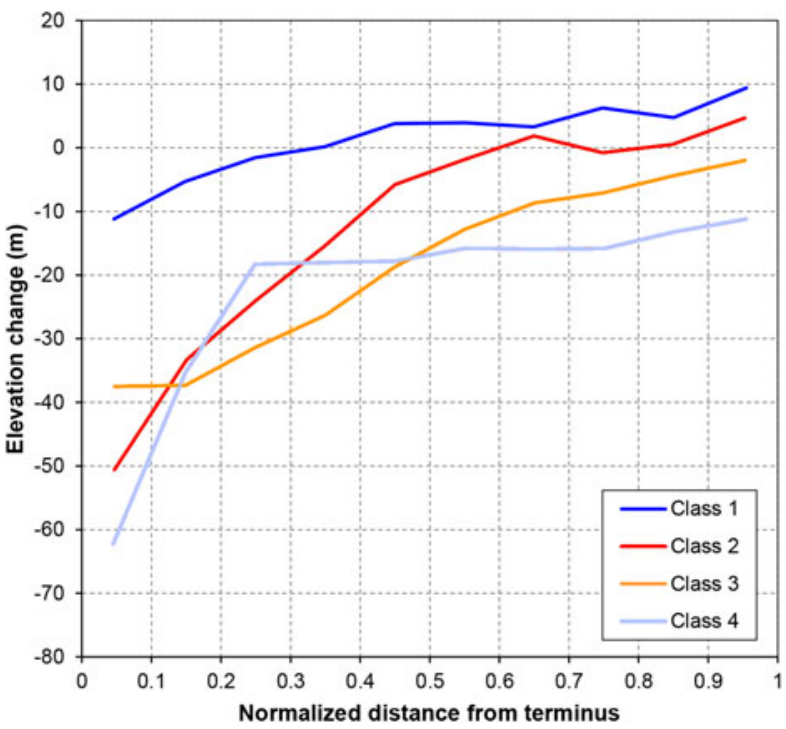

Fig. 5. Elevation change averaged along longitudinal profiles of Sample B glaciers, clustered into four elevation change pattern classes.

intermediate vulnerability is assigned to glaciers where they are of very local importance (class 3 ) or affect less than half of the glacier surface (class 2).

\subsection{Correlation analysis}

A correlation analysis was carried out to reveal major dependencies among variables expressing recent glacier behaviour, geometric adjustment and morphology. This analysis should provide a quantitative check of assumptions made in the selection of criteria for the combined GVI, and ease the interpretation of results. A correlation matrix was generated using the XLSTAT add-on for Microsoft Excel 2013. Variables expressing recent glacier

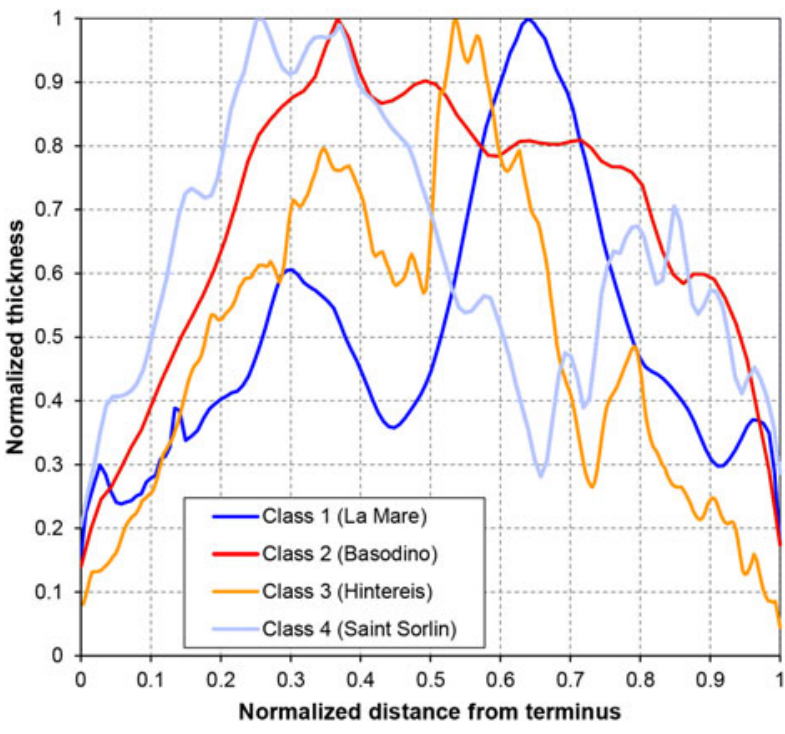

Fig. 6. Examples of normalised ice thickness vs normalised distance from the terminus, representing the four ITI classes of Sample B glaciers.

behaviour are the mean annual balance and mean AAR in the period from 2004 to 2013; geometric adjustments in the same period are characterised by $\%$ area change and perimeter change, separating areas above and below the median elevation; glacier morphology in early 2000s is expressed by mean elevation, median elevation, mean exposure, mean slope, elevation range (see Section 4.1), HI and AAR sensitivity (see Section 4.2).

\subsection{Mass-balance time series (Sample C)}

Mass-balance observations of Sample C, covering a common period of 50 years, were analysed in detail to identify long-term trends and peculiarities in glacier behaviour. In particular, we analysed (i) 

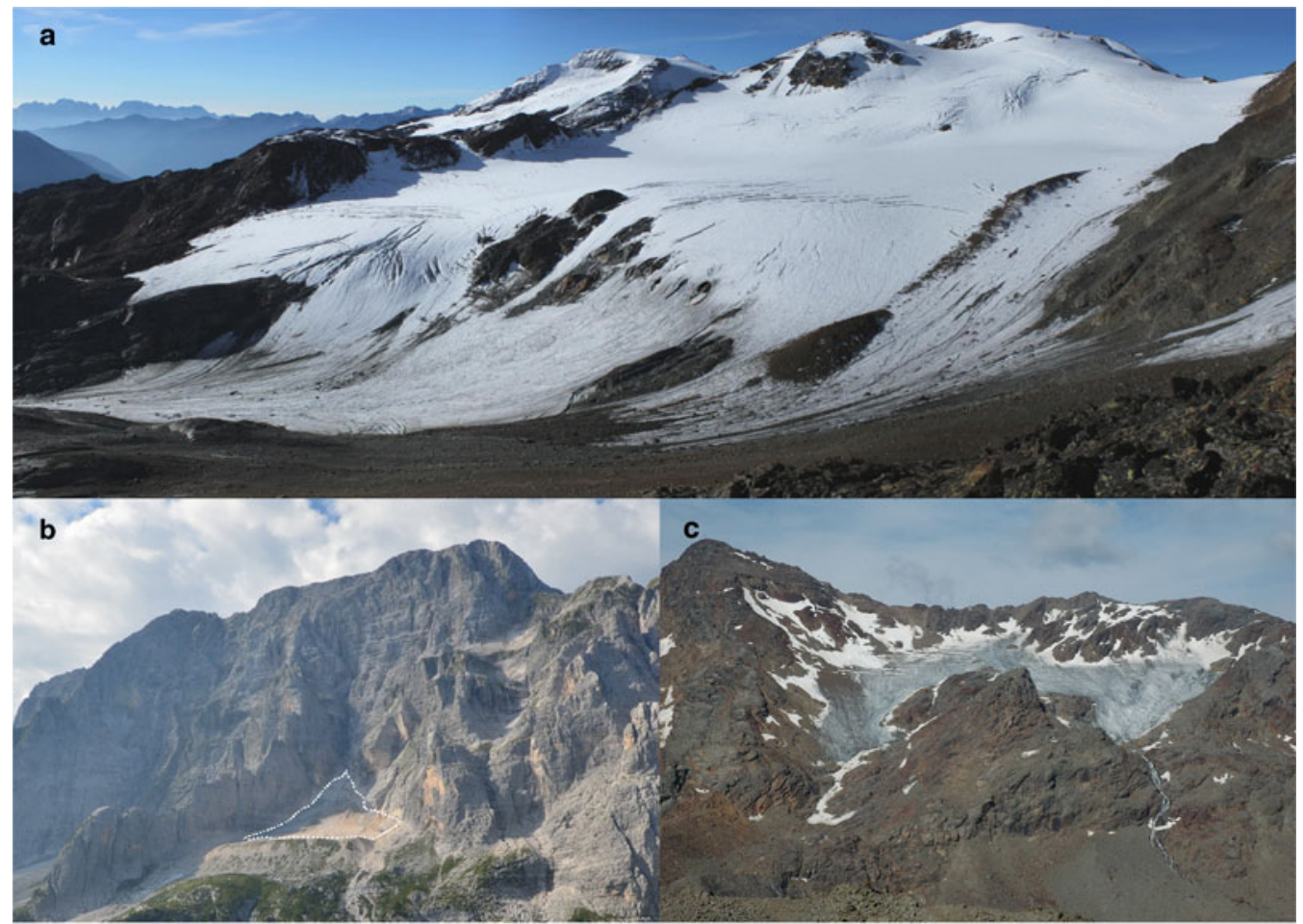

Fig. 7. Three mass-balance glaciers in the Italian Alps that show very different behaviour and vulnerability: (a) La Mare Glacier, where a bedrock step is separating the lower ablation zone and where a lake might form (photo, L. Carturan, 12 September 2018); (b) Montasio Glacier, which is heavily covered by debris, avalanche fed and shadowed by steep rock walls (photo, F. Cazorzi, 16 August 2012); (c) Fontana Bianca Glacier, whose imminent extinction led to the interruption of massbalance observation in 2018 (photo, C. Oberschmied, Agenzia per la Protezione civile - Provincia Autonoma di Bolzano - Alto Adige, 18 July 2018).

variability in annual mass balances, (ii) individual mass balance departures from the mean of the remaining glaciers and (iii) cumulative mass-balance departures. The latter might indicate possible mass-balance regime shifts from equilibrium response due to down-wasting, with an increasing impact of non-climatic controls on glacier mass balance. To obtain a better visual impression of the mass-balance variability for (ii), single-year values are presented in combination with a centred 5 -year moving average.

\section{Results}

\subsection{Topographic analysis}

The mass-balance glaciers analysed in this study (Sample B) vary in size from ice bodies smaller than $0.1 \mathrm{~km}^{2}$ (Pizol and Schwarzbach glaciers in Switzerland), to valley glaciers larger than $10 \mathrm{~km}^{2}$, reaching a maximum area of $17.2 \mathrm{~km}^{2}$ for Pasterze Glacier (Austria, Table S1). Overall, the frequency distribution of glacier sizes of Sample B is skewed towards larger area classes, compared to Sample A (Fig. 9). This is more evident considering frequency distributions by count (Fig. 9a) than by area (Fig. 9b). Hence, compared to the total sample of glaciers in the Alps (A) the sample of mass-balance glaciers (B) has relatively more of the larger glaciers included. This might seem surprising, but it directly results from the high number of glaciers smaller than $0.5 \mathrm{~km}^{2}$ in Sample A.

There is higher agreement in the frequency distributions of samples A and B when considering other morphometric variables. Their distribution is fairly similar and thus representative of the glaciers in the Alps. Sample B glaciers have a slightly higher elevation range (Figs 9c, d), lower mean elevation (Figs 9e, f) and lower slope (Figs 9g, h). The aspect distribution of Sample A is also well represented, with northern exposures prevailing in number for both samples (Fig. 9i). The area frequency distribution of aspect classes (Fig. 91) show lower agreement, due to the presence of large glaciers exposed to the East in Sample B (e.g. Pasterze, Malavalle and Hintereis).

The lowest HI values in Sample B are reached at Pasterze $(-2.25)$, Kesselwand (-2.13), Lunga $(-2.10)$ and Findelen $(-2.05)$ glaciers. These glaciers have the majority of their area in the upper part of their elevation range, and according to Jiskoot and others (2009) they are 'very top heavy'. The highest values of $\mathrm{HI}$ are found at Saint Sorlin and Pizol (both 2.04) as well as Wurten (1.85) glaciers, which are 'very bottom heavy' because most of their area lies in the lowest portion of the elevation range. Samples $\mathrm{B}$ and $\mathrm{C}$ have mean $\mathrm{HI}$ values of -0.43 and -0.45 , respectively, meaning that they are both globally 'equidimensional'. The hypsometry of Sample C is therefore representative of Sample B, considering also that Sample C includes Kesselwand and Saint Sorlin glaciers, which are at the two extremes in the range of variability of HI.

The correlation analyses applied to Sample B (Table S2) highlight how the HI alone does not explain the recent behaviour of glaciers, because it is not significantly correlated with the mean AAR, mean annual balance or other variables expressing their geometric changes. Hypsometry, however, influences the AAR sensitivity per unit change of ELA (see also Shea and Immerzeel, 2016), which results in close relationship with variables related to mass balance and area shrinkage. The correlation coefficients suggest that larger glaciers with higher elevation range have a lower AAR sensitivity and higher mean AAR in the observation period, which is in turn correlated to mass balance, as expected.

\subsection{Mass-balance time series}

Arithmetically averaged mass-balance values (Fig. 10) exhibit a high year-to-year variability. Balanced or positive mass budgets are common between 1967 and 1984, but become increasingly negative from 1985 to present. The extreme value of $-2.6 \mathrm{~m}$ in 


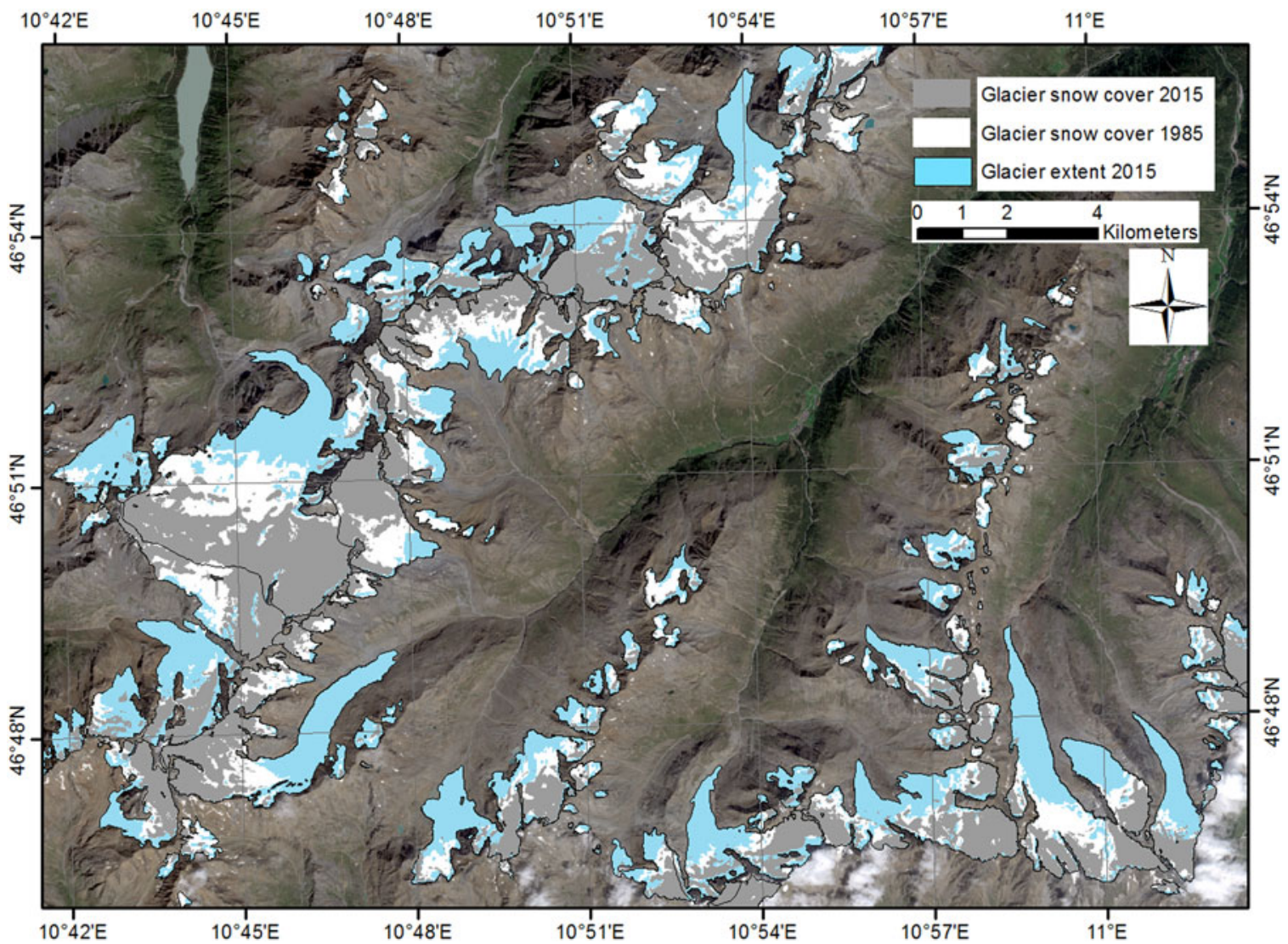

Fig. 8. End of summer snow cover as mapped from Landsat TM in 1985 (grey and white) and from Landsat OLI in 2015 (grey) using the method presented by Rastner and others (2019). Image source: Copernicus Sentinel data 2015.

the hot summer of 2003 (Schär and others, 2004) is the lowest on record. The standard deviation of reference glacier mass balances increases over the period of record, in particular after 2003, and is illustrated by the individual glacier mass-balance records (in grey).

Departures from the mean mass balance of the reference glaciers in Sample C show common regional trends and deviations (Fig. 11). When considering the 5-year running means, two peaks of positive departures are observed at the reference glaciers in France, three in the Ötztal Alps and for Careser, while no clear maxima are observed at Gries, Silvretta and Sonnblick glaciers. Thereby, the timing of the two peaks about 1980 and 1995 of Saint Sorlin and Sarennes fit to the local minima for the three Ötztal glaciers and Careser. Such deviations in opposite directions indicate a marked difference in the mass-balance forcing between the western and the eastern Alps. Assuming that the temperature forcing is similar for all glaciers, regional precipitation variability might explain the differences (Schwarb and others, 2001; Auer and others, 2007). A closer look at the values reveals further, more glacier specific differences: whereas the mass-balance differences of Silvretta and Kesselwand (to some extent also Sonnblick and Vernagt) are generally above zero (i.e. their mass budgets are more positive than the mean), Gries and Hintereis are mostly negative (Hintereis is mostly positive after 2000), Saint Sorlin was about the mean before 1995 and always negative afterwards, and Sarennes and Careser have always mass-balance values below the mean. This indicates that the glaciers might react to a common regional forcing regarding mass-balance variability, but individual factors are responsible for the absolute values.

The AAR and ELA values for the reference glaciers provide additional context for long-term glacier change. In general, there is an increasing trend in ELA values, which mostly rose above the glaciers' median elevations (dashed lines in Fig. 11) and reached the highest positions in the last decade. The AAR values show a large scatter and no clear trend for the glaciers with positive mass-balance deviations (Silvretta, Kesselwand and Sonnblick) and a clear negative trend for glaciers with negative deviations (Gries and Hintereis). Careser exhibits a switch in 1980 towards primarily zero AAR values. This coincides with ELAs above the median elevation of the glacier and increasingly negative mass-balance departures (Figs 11, 12a). From this we infer a regime shift in the mass balance for Careser. For Sarennes this shift can be derived from the mass-balance difference time series after 1995, when the negative differences started to steeply increase without recovering.

\subsection{Cumulative mass-balance differences}

Regime shifts can be better observed in the cumulative massbalance departures from the mean of Sample C (Fig. 12a). Cumulative departures are mostly positive for Kesselwand, Silvretta, Vernagt, Hintereis and Sonnblick glaciers, whereas increasingly negative departures are observed for Careser, Sarennes, Saint Sorlin and Gries glaciers. Increasingly negative cumulative departures begin in 1980 for Careser, 1995 for Sarennes, 2000 for Saint Sorlin and 1985 for Gries (though this is less pronounced). The differences between the glaciers are largely confirmed by the patterns of area and elevation changes. Although Careser, Sarennes and Saint Sorlin show large area and elevation losses at all elevations along with fragmentation (Fig. 3), shrinking of Vernagt, Sonnblick, Silvretta and Kesselwand is (in increasing order) restricted to the terminus region. Gries and Hintereis are in-between, i.e. substantial area and elevation losses occurred mostly in their ablation region, but tend to extend also higher up. 

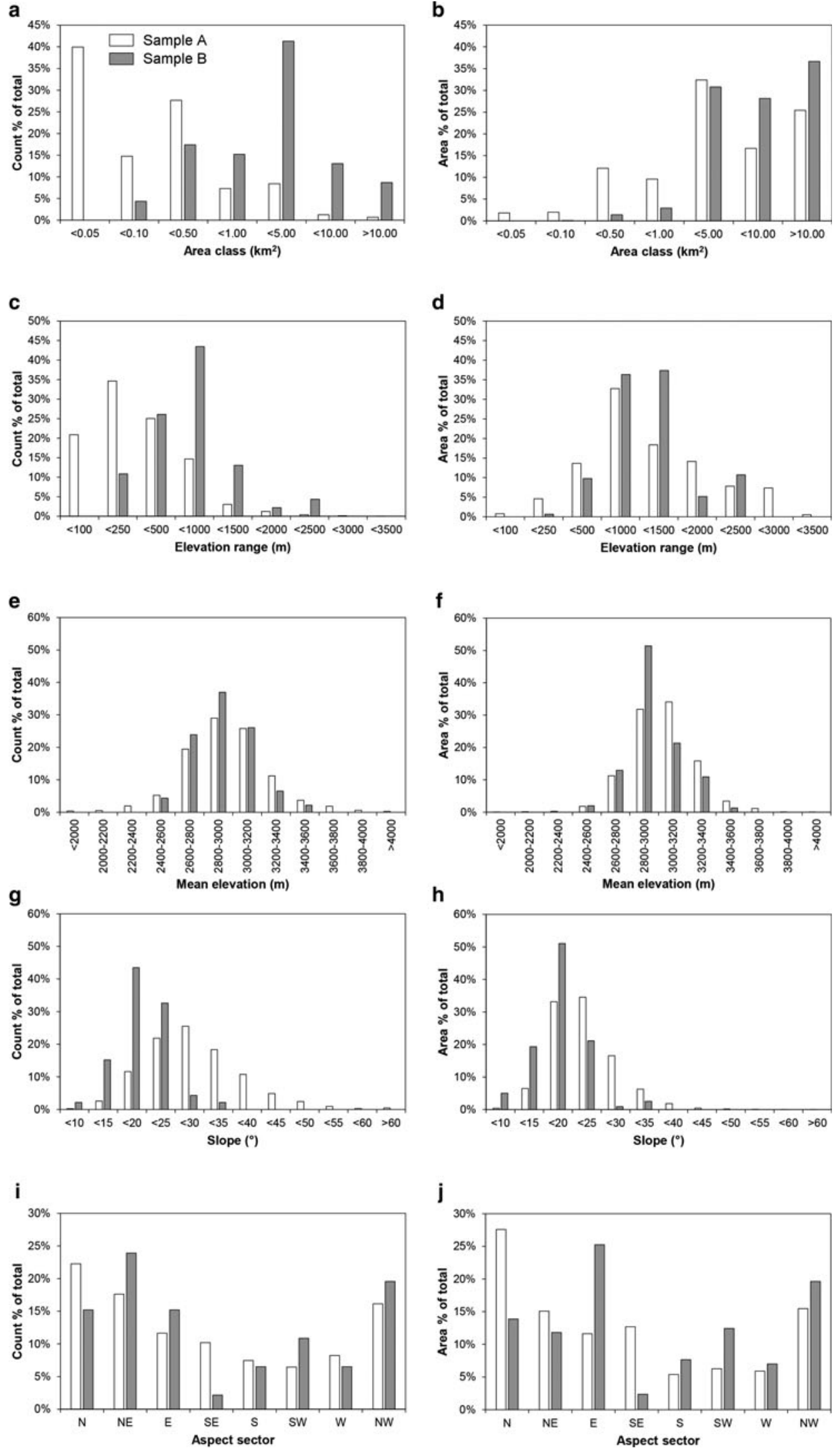

Fig. 9. Frequency distribution by count (left column) and area (right column) of glaciers of samples $A$ and $B$, for classes of area (a, b), elevation range (c, d), mean elevation $(e, f)$, slope $(g, h)$ and aspect $(i, l)$.

Cumulative differences in mass balance are also well reflected in the GVI classification (Fig. 12b). With only a few exceptions for glaciers with intermediate vulnerability, a high positive mass-balance deviation correlates with a low vulnerability index, and vice versa.

\subsection{Vulnerability index}

Figure 12b shows all glaciers of Sample B ordered by their GVI and colour-coded based on their class for the elevation change patterns (Fig. 5), with the three glaciers in class 1 that are among those with 
Fig. 10. Mean and std dev. of annual balance values for the nine

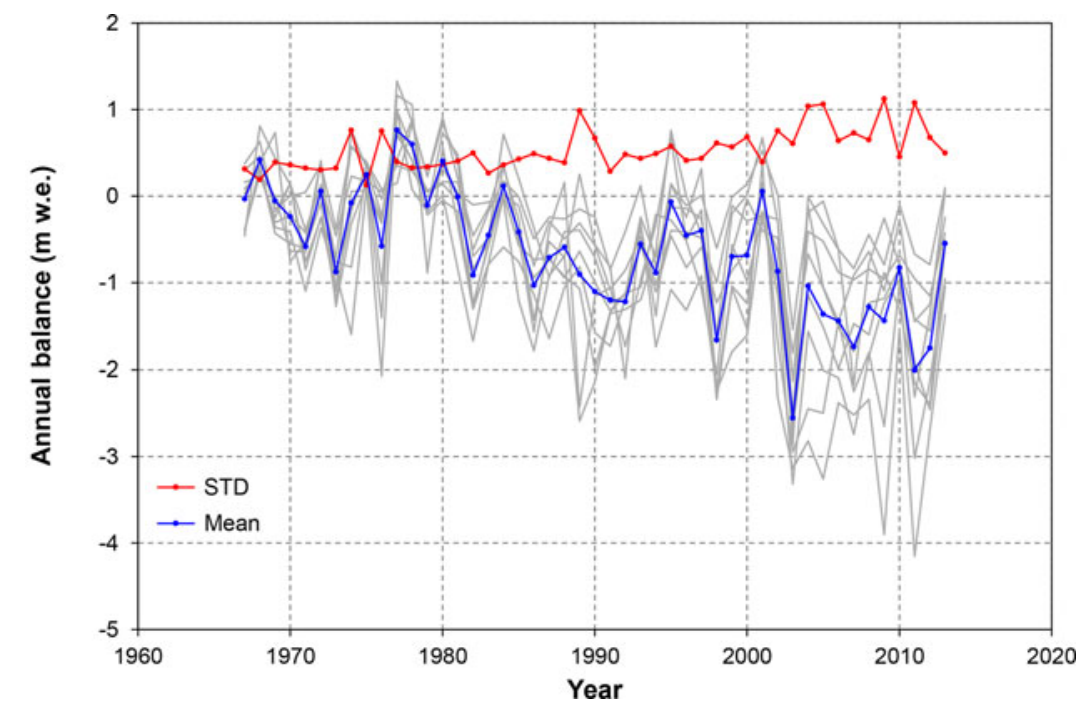
glaciers of Sample C from 1967 to 2013
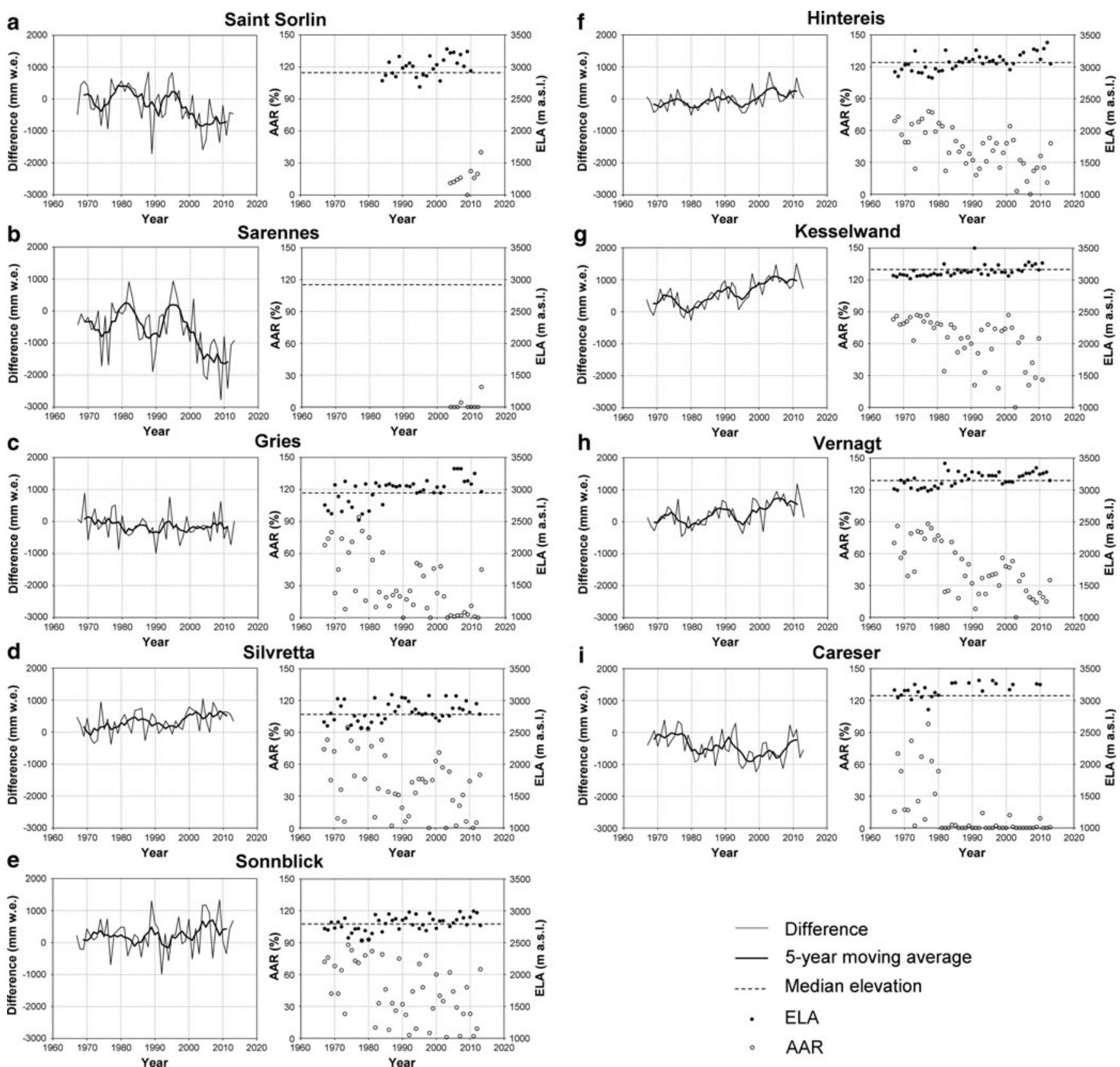

Fig. 11. Time series of the mass-balance differences of each glacier to the mean value of the other eight glaciers from Sample C. The right panel shows the respective series of annual ELA and AAR. 
Table 2. Count of each vulnerability criterion and class for the 46 mass-balance glaciers of the European Alps

\begin{tabular}{llrrrr}
\hline & & \multicolumn{3}{c}{ Vulnerability counting } \\
\cline { 3 - 6 } No. & \multicolumn{1}{c}{ Vulnerability criterion } & 1 & 2 & 3 & 4 \\
\hline 1 & Area Change Index (ACI) & 16 & 16 & 9 & 5 \\
2 & Elevation change pattern & 2 & 9 & 20 & 14 \\
3 & Ice Thicnkess Index (ITI) & 15 & 8 & 21 & 2 \\
4 & Slope changes & 8 & 10 & 15 & 13 \\
5 & Elevation range & 11 & 19 & 11 & 5 \\
6 & Hypsometric Index (HI) & 4 & 25 & 10 & 7 \\
7 & AAR sensitivity in the accumulation area & 2 & 15 & 22 & 7 \\
8 & AAR & 1 & 5 & 22 & 18 \\
9 & Avalanche, shadowing, debris cover & &
\end{tabular}

${ }^{\text {a }}$ Elevation range is calculated excluding the $2^{\text {nd }}$ and $98^{\text {th }}$ percentiles in the hypsometric curve.

lowest GVI, and 10 out of the 14 glaciers in class 4 that have the highest GVI values. The Argentière and Pasterze glaciers are significant exceptions, because they experienced large thinning compared to other glaciers ranked with low vulnerability. These two glaciers theoretically benefit from a high elevation range, low AAR sensitivity in their upper zone and favourable overall hypsometry. However, they are also characterised by a complex morphology, the progressive detachment of several tributaries and by a large and relatively thick tongue, which is thinning rapidly. Dynamic adjustments are likely also involved in the calculated elevation change patterns, but are not easy to quantify or distinguish from surface lowering caused by ablation.

The number of glaciers that have been assigned to the individual classes is summarised in Table 2. The majority of glaciers lie in the intermediate vulnerability classes ( 2 or 3 ) for most criteria, however their distribution is clearly skewed towards high vulnerability for elevation change patterns, mean AAR and for the aggregated avalanche-shadowing-debris cover criterion, whereas they show lower vulnerability for area change, ice thickness and HIs. Based on observed series of AAR, the upper limit of the GVI for glacier survival seems to be $\sim 25$.

\section{Discussion}

\subsection{Morphometric comparison}

In general, the mass-balance glaciers of the Alps have been selected in order to detect inter-annual ELA fluctuations (i.e. high elevation range and low AAR sensitivity), minimise the influence of local topo-climatic effects (i.e. area large enough) and at the same time maximise ease of access and safety during field operations, as suggested for example by Kaser and others (2003). These criteria highlight 'ideal' glaciers for direct massbalance measurements, but are rarely met together at the same glacier. For this reason, mass-balance glaciers selected in the past few decades fulfil only parts of these requirements. As shown in Section 5.1, the topographic characteristics of glaciers in Sample B are fairly representative of all glaciers in the Alps, but are a little skewed towards larger glaciers, with higher elevation range, lower slope and lower mean elevation. An optimal representativeness of Sample B glaciers would have been possible only when using reasoned sampling schemes, based for example on the frequency distribution of glaciers for selected morphometric variables. However, the consistent application of sampling schemes is difficult if not impossible because glacier morphometry is dynamic and changing constantly. In this context, the recent efforts to include smaller glaciers, and also those fed by avalanches, in the monitoring network are valuable (e.g. Scotti and others, 2014; Huss and Fischer, 2016), although their time series are less directly related to changes in climatic conditions because non-climatic controls on glacier mass balance increase with decreasing glacier area (see e.g. the Montasio Glacier in Fig. 7; Carturan and others, 2013b).

\subsection{Glacier behaviour and vulnerability}

The analysis of the nine long-term mass-balance series in the Alps (Sample C) clearly suggest that, starting in the 1980s and becoming more evident in the 1990s and 2000s, local effects and/or feedbacks started to impact individual glaciers. This is revealed by the increasing spread among mass-balance series (Fig. 10) and by the regime shifts visible in the series of mass-balance difference and cumulated difference from the mean (Figs 11 and 12). Local differences tend to be less pronounced with less negative mass balances (Fig. 10), for example in the years 2001, 2010 and 2013, whereas they increase with more negative mass balances, for example in 2009 and 2011. A notable exception to this rule is the very warm year 2003, when widespread record-low mass balance was associated with comparatively low inter-glacier variability, possibly highlighting that above a certain summer temperature, local effects (e.g. precipitation variability and glacier morphometry) tend to decrease their importance.

Among the analysed morphometric characteristics and changes, the decadal scale elevation change pattern is probably the most effective indicator of a single glaciers 'health' and massbalance development. This criterion has also been used by Pelto (2010) in a qualitative manner as an indicator of glacier health. In fact, we note that the four elevation change pattern classes described in Section 4.2.3 are closely related to the mean AAR in the observation period, which is highly correlated with the mean annual balance (Table S2). Class 1 glaciers underwent small changes in area and shrunk exclusively near their terminus (e.g. Kesselwand in Fig. 3), keeping a rather large accumulation area $(\overline{\mathrm{AAR}}=0.40$ on average), even though they are not sustainable for current glacier extents. Class 2 glaciers show small elevation changes in their upper part compared to the ablation area, and are characterised by $\overline{\mathrm{AAR}}$ values between 0.24 and 0.56 ( 0.37 on average) in the observation period (examples are Sonnblick and Vernagt in Fig. 3). Much smaller $\overline{\mathrm{AAR}}$ values are found in class 3 glaciers ( 0.23 on average), where thinning is significant also in the upper part, and which is the most numerous in Sample B. This class represents also the larger glaciers of Sample A, that have flat tongues at low elevations suffering the most from the mass loss since 2000. Impressive examples of separated valley glacier tongues can be found everywhere in the Alps, e.g. Pasterze, Roseg, Damma, Trift and Grindelwald glaciers. Glaciers in class 4, with disequilibrium response, were mostly below the ELA in the observation period $(\overline{\mathrm{AAR}}=0.17$ on average), because they are generally flat, located at low elevation and without topographic shadowing. In some cases they are also affected by unfavourable area and thickness distribution (i.e. bottom-heavy), such as Saint Sorlin in Figure 3. We observe that a classification of glacier behaviour and vulnerability is also possible with DEMs having a $30 \mathrm{~m}$ resolution, because the identification of the four main patterns has a limited dependence on correct absolute values of elevation change, and because class boundaries are not sharp and exceptions from the general picture of glacier retreat - such as the Belvedere Glacier (mini-)surge in 2001 (Haeberli and others, 2002) - exist. A broad classification is feasible even without multi-temporal DEMs, for example using area change patterns (Section 4.2.2) that result from the combined effect of ice thickness and elevation change distributions.

Collectively, the proposed GVI classification is a promising tool for assessment of glacier vulnerability. The GVI is based on the evidence that topographic characteristics have an important impact on mass-balance development (Furbish and Andrews, 


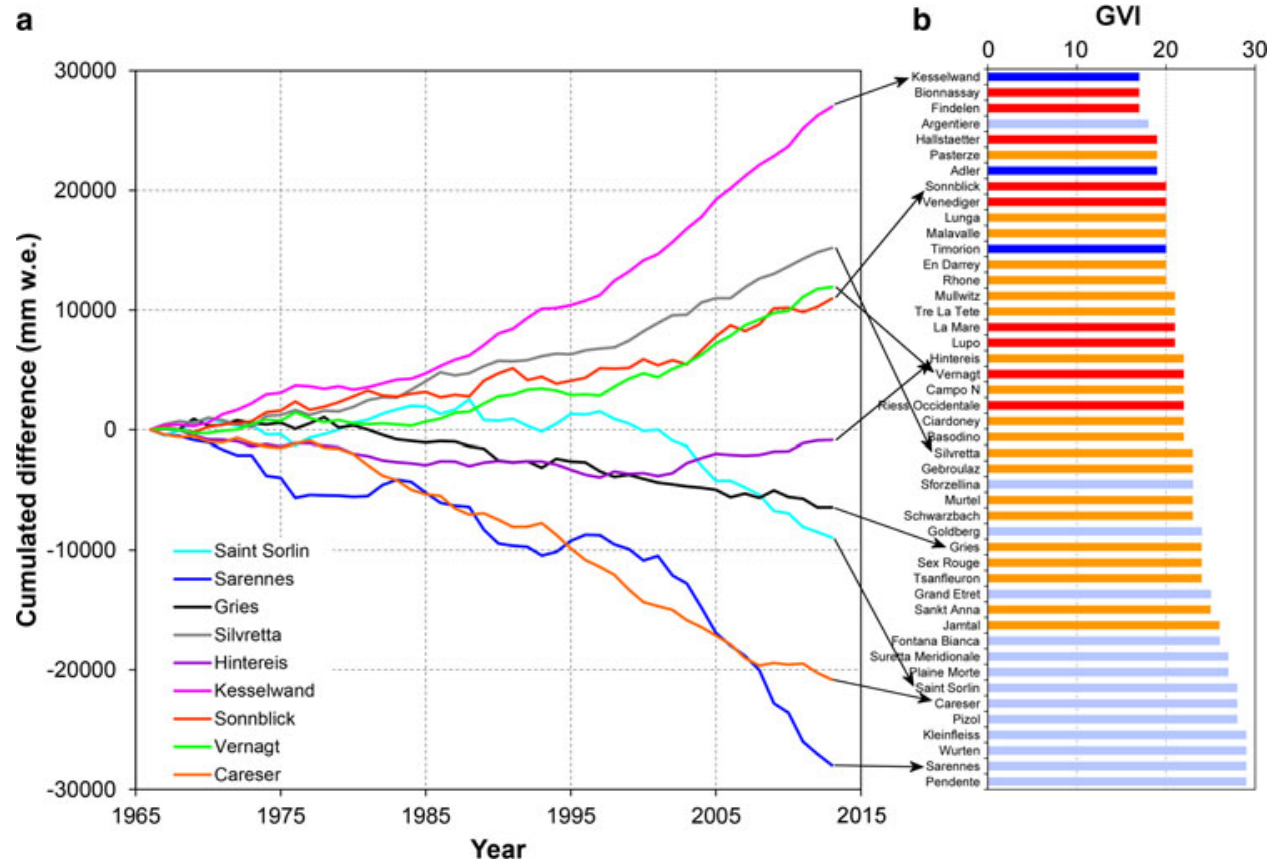

Fig. 12. Comparison of (a) time series of the cumulative mass-balance differences of each glacier to the mean value of the other eight glaciers from Sample $C$, and (b) the 46 glaciers of Sample B ranked for glacier vulnerability and colour-coded for elevation change pattern class (see Fig. 5 for colours).

1984; Paul and Haeberli, 2008; DeBeer and Sharp, 2009; Benn and Evans, 2010; Carturan and others, 2013c), and on the assumption that simple criteria, derived from remote-sensing imagery and DEMs, can be combined to classify glaciers according to their type of response and expected behaviour. This is also supported quantitatively by the results of our correlation analysis (Table S2 and Section 5.1), in particular for criteria expressing geometric adjustments and those related to glacier hypsometry (i.e. the elevation range and the AAR sensitivity per unit change of the ELA). Theoretically, low-resolution data should limit the applicability of the GVI for very small glaciers. Although the GVI has been developed for glaciers larger than $\sim 0.5 \mathrm{~km}^{2}$, the results indicate that the index can also be applied to small glaciers (Fig. 12 and Table S1). This is likely due to the combination of multiple criteria.

The nine criteria used here for a determination of the GVI have not been weighted although one can certainly argue that some of them are more important than others. Moreover, some of them are similar (e.g. HI and AAR sensitivity) but are not combined. We have thus tested several other criteria combinations (see Supplementary material), and while there are some small differences, the overall ranking of glacier vulnerability is robust. Uncertainties related to input datasets (see Section 6.3) or subjectivity in class threshold assignments may affect single criteria, but tend to level out when combining all GVI criteria. The GVI is thus considered as a robust index to determine glacier vulnerability. The proposed combination of criteria exploits a wide range of available information but maintains a reasonable degree of simplicity.

\subsection{Uncertainties}

For this study we have applied several datasets (glacier outlines, DEMs, ice thickness, mass balance and snow cover) in various combinations. Each of the datasets has an uncertainty that has been neglected so far. The main reason is the limited impact these uncertainties have on the results of the GVI classification. This is in part due to the analysis of patterns, trends and indices rather than absolute values. The former are much more robust and are not expected to change substantially when using different datasets. For example, instead of the DEMs and glacier outlines used here one could have also used other DEMs and/or outlines from other dates (both spanning a decadal time period) to observe the same pattern and derive the same class assignment. This is due to sustained shrinkage of glaciers in the Alps since about 1985 (Paul and others, 2020).

The area change patterns might also be influenced by wrongly included seasonal snow in outlines $\mathrm{O} 1$ and $\mathrm{O} 2$, but this can be excluded here as summer months in 2003, 2006, 2013 and 2015 had been very hot and nearly all off-glacier snow had melted. Glacier extents for analysed years should thus be accurate and the derived change pattern realistic.

The elevation change pattern is derived from two DEMs (SRTM and TanDEM-X) with a well-known significant radar penetration in snow. For Careser and La Mare glaciers we have thus compared elevation changes derived from these DEMs (Fig. 13a) with those derived from subtracting two LIDAR DEMs acquired in 2003 and 2013 (Fig. 13b). Careser represents glaciers that lack firn and snow in their upper part since the 1980s, whereas La Mare is representative of glaciers in active retreat, with preserved snow and firn in their upper zone in the past few decades (Carturan and others, 2013a; Carturan, 2016). Although the general pattern of elevation change is very similar, absolute values show a stronger overall thinning for the LIDAR difference, in particular for the upper region of La Mare Glacier. Accordingly, La Mare is in class 2 in our study and would be in class 3 according to the LIDAR difference map, indicating that our classification is on the conservative side (i.e. smaller vulnerability). Considering that the distinction among the four patterns takes into account not only the absolute elevation changes but also their elevation dependence and variability, possible errors in glacier ranking due to radar penetration are limited to classes 2 and 3, as shown for La Mare Glacier. Assuming that all class 2 glaciers are wrongly classified and actually belong to class 3 , as tested in a GVI experiment, lead to a vulnerability classification with the same results as in Figure 12.

The modelled ice thickness has an uncertainty of $\sim 30 \%$ compared to results from other methods and GPR measurements, but this uncertainty is not related to a specific zone of the glacier (Linsbauer and others, 2012). In consequence, the impact on 
a
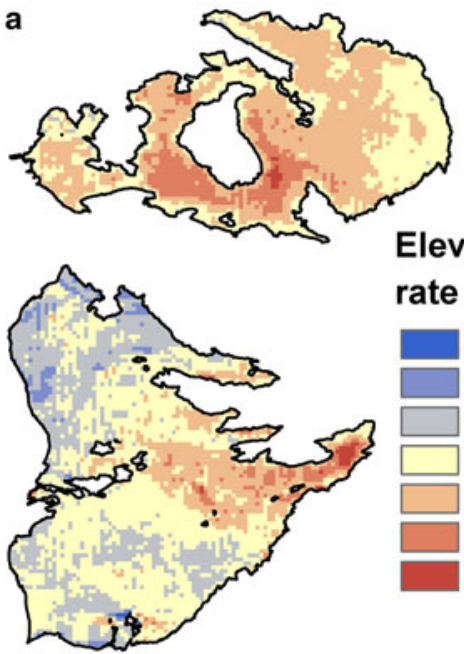

Elevation change

b rate $\left(\mathrm{m} \mathrm{a}^{-1}\right)$

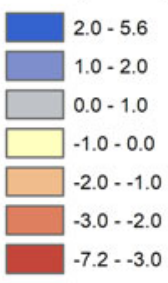

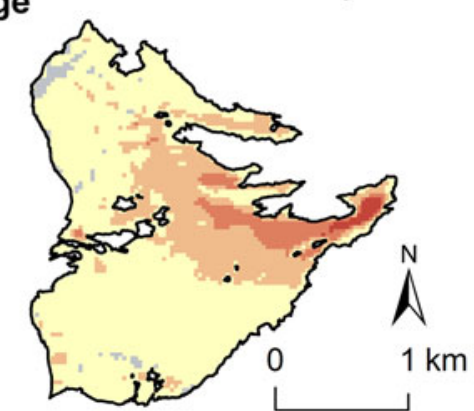

Fig. 13. Comparison between annual elevation change rate from (a) SRTM DEM and TanDEM-X DEM (period 2000-13), and (b) LiDAR surveys (period 2003-13), on the two neighbouring Careser (top row) and La Mare (bottom row) glaciers in the Italian Alps.

Table 3. Comparison between field measured AAR and SCF derived by classification of late summer Landsat imagery for different years and several mass-balance glaciers in the Alps

\begin{tabular}{|c|c|c|c|c|c|c|c|c|c|}
\hline Glacier & Year & AAR & SCF & SCF-AAR & Glacier & Year & AAR & SCF & SCF-AAR \\
\hline \multirow[t]{4}{*}{ Hallstätter } & 2008 & 0.49 & 0.59 & 0.10 & Kesselwand & 2004 & 0.61 & 0.53 & -0.08 \\
\hline & 2009 & 0.34 & 0.34 & 0.00 & & 2005 & 0.66 & 0.78 & 0.12 \\
\hline & 2012 & 0.32 & 0.40 & 0.08 & & 2010 & 0.65 & 0.47 & -0.18 \\
\hline & 2013 & 0.46 & 0.35 & -0.11 & Campo Nord & 2004 & 0.20 & 0.18 & -0.02 \\
\hline \multirow[t]{3}{*}{ Pasterze } & 2005 & 0.60 & 0.57 & -0.03 & & 2006 & 0.05 & 0.13 & 0.08 \\
\hline & 2006 & 0.47 & 0.47 & 0.00 & & 2009 & 0.26 & 0.18 & -0.08 \\
\hline & 2009 & 0.45 & 0.45 & 0.00 & La Mare & 2004 & 0.21 & 0.23 & 0.02 \\
\hline Mullwitz & 2009 & 0.37 & 0.39 & 0.02 & & 2009 & 0.33 & 0.30 & -0.03 \\
\hline Riess Occidentale & 2009 & 0.18 & 0.24 & 0.06 & Lupo & 2004 & 0.39 & 0.43 & 0.04 \\
\hline
\end{tabular}

The mean difference is 0.0 with a standard deviation of 0.08 .

the index (ITI) should be small. Slope changes as well as combined local criteria (avalanches, shadowing and debris cover) have been derived qualitatively and are thus largely independent of DEM uncertainties. The elevation range, HI and AAR sensitivities are all derived from a DEM with uncertainties (GDEM2), but they do not really impact on the classes assigned here, i.e. we would get similar classes with another DEM.

Finally, the mean AAR values for Sample C glaciers are mostly derived from field measurements and should thus be robust. For the glaciers in Sample B, 30\% of the values are derived from satellite data using the SCF proxy. Because the SCF values are expected to be larger than the AAR values, as satellite images were seldom acquired at the end of the ablation period, we did a comparison of SCF and AAR for several years and glaciers where both are available (Table 3). The comparison reveals that the generally small SCF overestimations tend to be compensated by underestimations due to SLC-off striping (ETM+ sensor after 2003) or shadows cast by clouds and rock walls, resulting in mean difference of zero and a standard deviation of 0.08 .

\subsection{Future perspectives}

Glaciers in the mass-balance monitoring network of the Alps (Sample B) are fairly representative of all other glaciers (apart from the rare largest ones), and they are similarly characterised by rapid down-wasting and eventual disappearance. Among Sample C glaciers, Sarennes is nearly extinct and Careser will likely follow shortly. The latter is still $\sim 60 \mathrm{~m}$ thick in the eastern part, but there is a lake forming at the front that is likely to accelerate glacier wastage. Without these two glaciers, the average mass balance of Sample C would have been $0.23 \mathrm{~m}$ less negative in the period from 2000 to 2013 ( -1.02 vs $-1.25 \mathrm{~m}$ w.e.), whereas between 1967 and 1980 the two means were almost identical (0.063 vs $-0.005 \mathrm{~m}$ w.e.). The high imbalance and nonlinear response of these two glaciers is therefore affecting significantly the glaciological mass-balance estimates from reference glaciers at the mountain range scale, and will result in a discontinuity in the time series when the two glaciers have vanished and/or will be replaced with glaciers having less negative mass-balance values.

There is a significant number of monitored glaciers in the Alps experiencing the same fate (Fig. 12). They were missing a significant accumulation area for a long time and after decades of strong mass loss they are considerably smaller, thinner and changed in shape compared to when measurements begun. In some cases (e.g. Sforzellina) negative feedbacks from increasing debris cover and avalanche contribution tend to preserve the residual ice bodies, but other glaciers are at the final stage of becoming extinct. This can lead to increased complexity in performing observations and also calculating reasonable glacier-wide mass balances from the remaining network of stakes (e.g. some elevation intervals might no longer be covered by ice). In 2018, for example, massbalance measurements were discontinued on the Fontana Bianca Glacier (Fig. 7c, where they started in 1983), because of the rockfall danger and low regional representativeness.

It can also be assumed that the formation of pro-glacial lakes in overdeepenings of the glacier bed (e.g. Paul and others, 2007; Frey and others, 2010; Emmer and others, 2015) will continue in the future (e.g. Linsbauer and others, 2012; Haeberli and others, 
2016) and considerably enhance glacier retreat for numerous glaciers (e.g. Purdie and Fitzharris, 1999). This effect has only indirectly been considered in the GVI (e.g. via the criteria slope changes and HI) but might be in particular important for larger valley glaciers with flat tongues. However, pro-glacial lake formation depends on the (unknown) details of the bed topography. Moreover, lakes might impact on glacier retreat only for a limited amount of time as overdeepenings are often locally constrained. We have thus not considered it in our simplified index calculation.

Combined indexes such as the GVI might be used for early detection of glaciers at risk of extinction in the near-future and possible candidates with higher chance to survive, to be evaluated as possible replacements for currently monitored glaciers or other long-term investigations. Moreover, the index can be used to determine if the mass balance of a glacier will be impacted sooner or later by factors other than climate. This information can be used to develop a longer-term perspective of mass-balance measurements for the currently selected glaciers, but also to pre-select such glaciers in other regions of the world. Test of GVI versions with a reduced number of criteria indicate that they might also be applied reliably in the case of reduced data availability, or possibly in a semi-automatic fashion over a large number of glaciers. In particular, we obtained a classification that is very similar to the GVI presented in Figure 12 when removing all criteria dependent on DEM availability (i.e. elevation change pattern, HI, ITI and AAR sensitivity in the accumulation area), or all criteria that require multi-temporal observations $(\mathrm{ACI}, \overline{\mathrm{AAR}}$ and elevation change pattern). Comparing the GVI with single criteria revealed that good results can be achieved using the elevation change pattern alone, and very good results are obtained using the AAR sensitivity in the accumulation area (resulting in no arrow crossings when connecting the nine cumulative mass-balance differences to the glaciers ranked for GVI).

In hind cast, it might also be possible to decide about the removal of specific glaciers from the sample of reference glaciers that is used for region-wide mass-balance averaging. However, to be fully aware of a possible regime shift (as shown for the Careser Glacier) and the impacts of climatic variability on such glacier remnants, it is important to continue and report field measurements on the remaining ice as long as possible.

The removal/replacement of existing series is not trivial. First, class 4 glaciers contribute an important part of the climatic response of the glacier system in the Alps, and their (sudden) exclusion would imply a step change in mountain range mass-balance estimates (unless the non-climatic response is identified and adjusted in its early stages), and a spurious shift towards a less negative mean budget. However, current approaches to extrapolate measured mass balances to a larger sample (Zemp and others, 2019) are less dependent on the absolute values (that are taken from geodetic measurements) than on their temporal variability. The latter seems to be synchronous for some time, even if a glacier is close to disappearance. Hence, using mass-balance variability is less impacted by lingering glacier disappearance than absolute values. However, one has to be aware that over elongated mountain ranges such as the Alps, where different sub-regions can experience opposite effect from the same atmospheric circulation patterns (in particular regarding precipitation amounts), large differences in the mass-balance variability exist. The two glaciers in the French Alps have basically the opposite variability (deviation from the mean) compared to the three in the Ötztal Alps, Careser and Sonnblick (Fig. 11). Just using either group would thus give a different picture of the regional mass-balance variability. The common climatic forcing that has been proposed for the glaciers in the Alps (e.g. Vincent and others, 2017) is thus potentially modified by regional variability in precipitation and cloud cover (Quadrelli and others, 2001;
Schmidli and others, 2002; Brunetti and others, 2006, 2009; Auer and others, 2007).

\section{Conclusions}

In this study we have analysed the morphometric and mass-balance characteristics of the mass-balance glaciers that are currently measured in the Alps. We developed an index (GVI) to determine their resilience to climatic changes. The investigation was motivated by the loss of mass-balance glaciers and the need to replace them with glaciers that are more resilient in good time. The GVI is derived from glacier outlines and a DEM (e.g. breaks in slope and $\mathrm{HI}$ ) in combination with criteria derived from multi-temporal data (e.g. area and elevation changes and snow cover) and modelling (ice thickness distribution). The index assignment was developed for the Alps but can be adjusted to other regions. Overall, we found a very good agreement between the GVI and the ranked cumulative deviations of the mass balance from the nine glaciers with long-term measurements, providing confidence in its wider applicability. For the next few decades the GVI can also be used when searching for glaciers that might replace in the future those in the current selection or new ones.

For a few glaciers (Careser, Sarennes and Saint Sorlin) we identified regime shifts in their mass-balance time series indicating the increasing impact of non-climatic controls on their mass balance, and likely leading to too negative values of the Alpine wide average afterwards (by $\sim 0.2 \mathrm{~m}$ w.e.). Just removing them from the sample is, however, not straight forward as these shifts can only be identified in hindsight. This requires continuing measurements also on disintegrating glaciers for several years. At best, such measurements are performed in parallel with the replacement glacier to learn about the differences of the new time series. The direct comparison of the mass-balance differences reveals interesting deviations and common patterns on a regional scale, indicating that regional differences under meteorological conditions (e.g. precipitation amounts) might be responsible for it. Overall, the glaciers currently selected for mass-balance measurements (Sample B) reflect the key geomorphologic characteristics of the entire sample very well, but are biased towards somewhat larger glaciers in relative terms. Despite this good representativeness, very large glaciers (e.g. Aletsch, Gorner and Unteraar) are missing and their strong mass loss at low elevations (though having a high albedo or thick debris cover) is not well captured by the current sample. Unconsidered characteristics such as response times or lake formation might have to be added when choosing a new observation site.

Supplementary material. The supplementary material for this article can be found at https://doi.org/10.1017/jog.2020.71

Acknowledgements. L.C. acknowledges funding from the University of Padova Senior Research Grant: 'Impact of climatic fluctuations on snowand ice-dominated alpine watersheds: effects on the cryosphere and hydrology'. The 2006-2007 outlines of Italian glaciers data were furnished by Maria Cristina Salvatore (project of strategic interest CNR-NEXTDATA, PI Antonello Provenzale CNR-IGG, WP 1.6, Carlo Baroni UNIPI). P.R. and F.P. acknowledge funding from the ESA project Glaciers_cci (4000109873/ 14/I-NB) and the Copernicus Climate Change Service (C3S) that is funded by the European Union and implemented by ECMWF. The TanDEM-X DEM has been acquired by the TerraSAR-X/TanDEM-X mission and is provided by DLR (DEM_GLAC1823). We also thank Matthias Huss from the ETH Zurich for providing the ice thickness distribution data for the glaciers in the Alps, and Wilfried Haeberli and Michael Zemp for their suggestions.

\section{References}

Auer I and 31 others (2007) HISTALP - historical instrumental climatological surface time series of the Greater Alpine region. International Journal of Climatology 27(1), 17-46. doi:10.1002/joc.1377. 
Barletta VR and 5 others (2006) Glacier shrinkage and modeled uplift of the Alps. Geophysical Research Letters 33(14), L14307. doi:10.1029/2006GL026490.

Benn DI and Evans DJA (2010) Glaciers and Glaciation. London: Hodder Education. http://doi.wiley.com/10.1111/j.1502-3885.2011.00212.x.

Brunetti $\mathbf{M}$ and 5 others (2006) Precipitation variability and changes in the Greater Alpine region over the 1800-2003 period. Journal of Geophysical Research 111, D11107. doi:10.1029/2005JD006674.

Brunetti M and 6 others (2009) Climate variability and change in the Greater Alpine region over the last two centuries based on multi-variable analysis. International Journal of Climatology 29, 2197-2225. doi:10.1002/joc.1857.

Carturan L and 11 others (2013a) Decay of a long-term monitored glacier: Careser Glacier (Ortles-Cevedale, European Alps). Cryosphere 7(6), 18191838. doi:10.5194/tc-7-1819-2013.

Carturan L and 11 others (2013b) Current behaviour and dynamics of the lowermost Italian glacier (Montasio Occidentale, Julian Alps). Geografiska Annaler: Series A, Physical Geography 95(1), 79-96. doi:10.1111/geoa.12002.

Carturan L and 10 others (2013c) Area and volume loss of the glaciers in the Ortles-Cevedale group (Eastern Italian Alps): controls and imbalance of the remaining glaciers. Cryosphere 7(5), 1339-1359. doi:10.5194/tc-7-1339-2013.

Carturan L (2016) Replacing monitored glaciers undergoing extinction: a new measurement series on La Mare Glacier (Ortles-Cevedale, Italy). Journal of Glaciology 62(236), 1093-1103. doi:10.1017/jog.2016.107.

Carturan L and 6 others (2019) Relevance and scale dependence of hydrological changes in glacierized catchments: insights from historical data series in the eastern Italian Alps. Water 11(1), 89. doi:10.3390/w11010089.

Carturan L, Cazorzi F, De Blasi F and Dalla Fontana G (2015) Air temperature variability over three glaciers in the Ortles-Cevedale (Italian Alps): effects of glacier fragmentation, comparison of calculation methods, and impacts on mass balance modeling. Cryosphere 9(3), 1129-1146. doi:10. 5194/tc-9-1129-2015.

Casassa G, López P, Pouyaud B and Escobar F (2009) Detection of changes in glacial run-off in alpine basins: examples from North America, the Alps, central Asia and the Andes. Hydrological Processes 23(1), 31-41. doi:10. 1002/hyp.7194.

Cogley and 10 others (2011) Glossary of Glacier Mass Balance and Related Terms. IHP-VII Technical Documents in Hydrology 86, IACS Contribution No. 2, UNESCO-IHP, 114pp. https://unesdoc.unesco.org/ark:/48223/pf0000192525.

DeBeer CM and Sharp MJ (2009) Topographic influences on recent changes of very small glaciers in the Monashee Mountains, British Columbia, Canada. Journal of Glaciology 55(192), 691-700. doi:10.3189/002214309789470851.

Dietrich $\mathbf{R}$ and 5 others (2010) Rapid crustal uplift in Patagonia due to enhanced ice loss. Earth and Planetary Science Letters 289(1-2), 22-29. doi:10.1016/j.epsl.2009.10.021.

Dyurgerov M, Meier MF and Bahr DB (2009) A new index of glacier area change: a tool for glacier monitoring. Journal of Glaciology 55(192), 710 716. doi:10.3189/002214309789471030.

Emmer A, Merkl S and Mergili M (2015) Spatiotemporal patterns of highmountain lakes and related hazards in western Austria. Geomorphology 246, 602-616. doi:10.1016/j.geomorph.2015.06.032.

Evatt GW and 7 others (2015) Glacial melt under a porous debris layer. Journal of Glaciology 61(229), 825-836. doi:10.3189/2015JoG14J235.

Forel FA (1895) Les variations périodiques des glaciers. Discours préliminaire. Archives des Sciences Physiques et Naturelles XXXIV, 209-229.

Frey H, Haeberli W, Linsbauer A, Huggel C and Paul F (2010) A multi-level strategy for anticipating future glacier lake formation and associated hazard potentials. Natural Hazards and Earth System Sciences 10, 339-352. doi:10. 5194/nhess-10-339-2010.

Furbish DJ and Andrews JT (1984) The use of hypsometry to indicate long term stability and response of valley glaciers to changes in mass transfer. Journal of Glaciology 30(105), 199-211. doi:10.3189/S0022143000005931.

Galos SP and 8 others (2017) Reanalysis of a 10-year record (2004-2013) of seasonal mass balances at Langenferner/Vedretta Lunga, Ortler Alps, Italy. Cryosphere 11(3), 1417-1439. doi:10.5194/tc-11-1417-2017.

Gardner AS and 15 others (2013) A reconciled estimate of glacier contributions to sea level rise: 2003 to 2009. Science (New York, N.Y.) 340(6134), 852-857. doi:10.1126/science.1234532.

Giesen RH and Oerlemans J (2013) Climate-model induced differences in the 21st century global and regional glacier contributions to sea-level rise. Climate Dynamics 7, 3283-3300. doi:10.1007/s00382-013-1743-7.

Goosse $\mathbf{H}$ and 7 others (2018) Testing the consistency between changes in simulated climate and Alpine glacier length over the past millennium. Climate of the Past 14(8), 1119-1133. doi:10.5194/cp-14-1119-2018.
Greuell W and Böhm R (1998) $2 \mathrm{~m}$ Temperatures along melting midlatitude glaciers, and implications for the sensitivity of the mass balance to variations in temperature. Journal of Glaciology 44(146), 9-20. doi:10.3189/ S0022143000002306.

Greuell W, Knap WH and Smeets PC (1997) Elevational changes in meteorological variables along a midlatitude glacier during summer. Journal of Geophysical Research 102(D22), 25941-25954. doi:10.1029/97JD02083.

Grünewald K and Scheithauer J (2010) Europe's southernmost glaciers: response and adaptation to climate change. Journal of Glaciology 56(195), 129-142. doi:10.3189/002214310791190947.

Haeberli W and 7 others (2002) A surge-type movement at Ghiacciaio del Belvedere and a developing slope instability in the east face of Monte Rosa, Macugnaga, Italian Alps. Norsk Geografisk Tidsskrift - Norwegian Journal of Geography 56(2), 104-111. doi:10.1080/002919502760056422.

Haeberli W and Hoelzle M (1995) Application of inventory data for estimating characteristics of and regional climate-change effects on mountain glaciers: a pilot study with the European Alps. Annals of Glaciology 21, 206212. doi:10.3189/S0260305500015834.

Haeberli W, Hoelzle M, Paul F and Zemp M (2007) Integrated monitoring of mountain glaciers as key indicators of global climate change: the European Alps. Annals of Glaciology 46(1), 150-160. doi:10.3189/172756407782871512.

Haeberli W, Huggel C, Paul F and Zemp M (2013) 13.10 Glacial responses to climate change. In Shroder JF James LA Harden CP and Clague JJ (eds). Treatise on Geomorphology. San Diego, CA: Academic Press. Vol. 13. Geomorphology of Human Disturbances, Climate Change, and Natural Hazards.

Haeberli W, Linsbauer A, Cochachin A, Salazar C and Fischer UH (2016) On the morphological characteristics of overdeepenings in high-mountain glacier beds: morphology of glacier-bed overdeepenings. Earth Surface Processes and Landforms 41(13), 1980-1990. doi:10.1002/esp.3966.

Haeberli W, Oerlemans J and Zemp M (2019) The future of alpine glaciers and beyond. Oxford Research Encyclopedia of Climate Science. New York: Oxford University Press. doi:10.1093/acrefore/9780190228620.013.769.

Holzhauser H, Magny MJ and Zumbühl HJ (2005) Glacier and lake-level variations in west-central Europe over the last 3500 years. The Holocene 15(6), 789-801. doi:10.1191/0959683605hl853ra.

Huggel C, Carey M, Clague JJ and Kääb A (2015) The High-Mountain Cryosphere: Environmental Changes and Human Risks. Cambridge: Cambridge University Press. doi:10.1017/CBO9781107588653.

Huss M (2011) Present and future contribution of glacier storage change to runoff from macroscale drainage basins in Europe. Water Resources Research 47(7), 1-14. doi:10.1029/2010WR010299.

Huss M, Dhulst L and Bauder A (2015) New long-term mass-balance series for the Swiss Alps. Journal of Glaciology 61(227), 551-562. doi:10.3189/ 2015JoG15J015.

Huss M and Farinotti D (2012) Distributed ice thickness and volume of all glaciers around the globe. Journal of Geophysical Research 117(F4), F04010. doi:10.1029/2012JF002523.

Huss $\mathbf{M}$ and Fischer M (2016) Sensitivity of very small glaciers in the Swiss Alps to future climate change. Frontiers in Earth Science 4, 34. doi:10. 3389/feart.2016.00034.

Huss M and Hock R (2015) A new model for global glacier change and sealevel rise. Frontiers in Earth Science 3, 54. doi:10.3389/feart.2015.00054.

Isotta FA and 17 others (2014) The climate of daily precipitation in the Alps: development and analysis of a high-resolution grid dataset from pan-Alpine rain-gauge data. International Journal of Climatology 34(5), 1657-1675. doi: $10.1002 /$ joc. 3794 .

Jiskoot H, Curran CJ, Tessler DL and Shenton LR (2009) Changes in Clemenceau Icefield and Chaba Group glaciers, Canada, related to hypsometry, tributary detachment, length-slope and area-aspect relations. Annals of Glaciology 50(53), 133-143. doi:10.3189/172756410790595796.

Kaser G, Fountain A and Jansson P (2003) A Manual for Monitoring the Mass Balance of Mountain Glaciers. Paris: UNESCO. http://www.hydrologie.org/BIB/Publ_UNESCO/TD_059_2003.pdf.

Kaser G, Grosshauser M and Marzeion B (2010) Contribution potential of glaciers to water availability in different climate regimes. Proceedings of the National Academy of Sciences 107(47), 20223-20227.

Kotlarski S and 15 others (2014) Regional climate modeling on European scales: a joint standard evaluation of the EURO-CORDEX RCM ensemble. Geoscientific Model Development 7(4), 1297-1333. doi:10.5194/gmd-7-1297-2014.

Kuhn M (1985) Fluctuations of climate and mass balance: different responses of two adjacent glaciers. Zeitschrift für Gletscherkunde und Glazialgeologie 21, 409-416. 
Kuhn M (1995) The mass balance of very small glaciers. Zeitschrift für Gletscherkunde und Glazialgeologie 31(1-2), 171-179.

Leigh JR and 5 others (2019) Identifying and mapping very small $\left(<0.5 \mathrm{~km}^{2}\right)$ mountain glaciers on coarse to high-resolution imagery. Journal of Glaciology 65(254), 873-888. doi:10.1017/jog.2019.50.

Linsbauer A, Paul F and Haeberli W (2012) Modeling glacier thickness distribution and bed topography over entire mountain ranges with GlabTop: application of a fast and robust approach. Journal of Geophysical Research 117(F3), F03007. doi:10.1029/2011JF002313.

Lutz AF, Immerzeel WW, Kraaijenbrink PDA, Shrestha AB and Bierkens MFP (2016) Climate change impacts on the upper Indus hydrology: sources, shifts and extremes. PLOS ONE 11(11), e0165630. doi:10.1371/journal.pone.0165630.

Mark BG and Fernández A (2017) The significance of mountain glaciers as sentinels of climate and environmental change. Geography Compass 11 (6), e12318. doi:10.1111/gec3.12318.

Marzeion B, Jarosch AH and Hofer M (2012) Past and future sea-level change from the surface mass balance of glaciers. Cryosphere 6(6), 12951322. doi:10.5194/tc-6-1295-2012.

Mölg N and 5 others (2017) Ten years of monthly mass balance of Conejeras Glacier, Colombia, and their evaluation using different interpolation methods. Geografiska Annaler: Series A, Physical Geography 99(2), 155-176. doi:10.1080/04353676.2017.1297678.

Oerlemans J (2005) Extracting a climate signal from 169 glacier records. Science (New York, N.Y.) 308(5722), 675-677. doi:10.1126/science.1107046.

Parkes D and Marzeion B (2018) Twentieth-century contribution to sea-level rise from uncharted glaciers. Nature 563(7732), 551-554. doi:10.1038/ s41586-018-0687-9.

Paul F and 9 others (2009) Recommendations for the compilation of glacier inventory data from digital sources. Annals of Glaciology 50(53), 119-126. doi:10.3189/172756410790595778.

Paul F, Frey H and Le Bris R (2011) A new glacier inventory for the European Alps from Landsat TM scenes of 2003: challenges and results. Annals of Glaciology 52(59), 144-152. doi:10.3189/172756411799096295.

Paul F and Haeberli W (2008) Spatial variability of glacier elevation changes in the Swiss Alps obtained from two digital elevation models. Geophysical Research Letters 35(21), L21502. doi:10.1029/2008GL034718.

Paul F, Kääb A and Haeberli W (2007). Recent glacier changes in the Alps observed by satellite: consequences for future monitoring strategies. Global and Planetary Change 56(1-2), 111-122. doi:10.1016/j.gloplacha.2006.07.007.

Paul F, Kääb A, Maisch M, Kellenberger T and Haeberli W (2004) Rapid disintegration of Alpine glaciers observed with satellite data. Geophysical Research Letters 31(21), L21402. doi:10.1029/2004GL020816.

Paul F, Rastner P, Azzoni RS, Diolaiuti G, Fugazza D, Bris Le, Nemec R, Rabatel J, Ramusovic A, Schwaizer M and Smiraglia G (2020) Glacier shrinkage in the Alps continues unabated as revealed by a new glacier inventory from Sentinel-2. Earth Syst. Sci. Data 12, 1805-1821. doi: 10. 5194/essd-12-1805-2020.

Pelto MS (2010) Forecasting temperate alpine glacier survival from accumulation zone observations. Cryosphere 4(1), 67-75. doi:10.5194/tc-4-67-2010.

Prinz R, Heller A, Ladner M, Nicholson L and Kaser G (2018) Mapping the loss of Mt. Kenya's glaciers: an example of the challenges of satellite monitoring of very small glaciers. Geosciences 8(5), 174. doi:10.3390/geosciences8050174.

Purdie J and Fitzharris B (1999) Processes and rates of ice loss at the terminus of Tasman Glacier, New Zealand. Global and Planetary Change 22 (1-4), 79-91. doi:10.1016/S0921-8181(99)00027-2.

Quadrelli R, Lazzeri M, Cacciamani C and Tibaldi S (2001) Observed winter Alpine precipitation variability and links with large-scale circulation patterns. Climate Research 17, 275-284. doi:10.3354/cr017275.

Radić V and 5 others (2014) Regional and global projections of twenty-first century glacier mass changes in response to climate scenarios from global climate models. Climate Dynamics 42(1-2), 37-58. doi:10.1007/ s00382-013-1719-7.

Ramirez E and 8 others (2001) Small glaciers disappearing in the tropical Andes: a case study in Bolivia: Glaciar Chacaltaya $\left(16^{\circ} \mathrm{S}\right)$. Journal of Glaciology 47(157), 187-194. doi:10.3189/172756501781832214.

Rastner P and 6 others (2019) On the automated mapping of snow cover on glaciers and calculation of snow line altitudes from multi-temporal Landsat data. Remote Sensing 11(12), 1410. doi:10.3390/rs11121410.
Rastner P, Joerg PC, Huss M and Zemp M (2016) Historical analysis and visualization of the retreat of Findelengletscher, Switzerland, 1859-2010 Global and Planetary Change 145, 67-77. doi: 10.1016/j.gloplacha.2016.07.005.

Reid PC and 28 others (2016) Global impacts of the 1980s regime shift. Global Change Biology 22(2), 682-703. doi:10.1111/gcb.13106.

Ritter F, Fiebig M and Muhar A (2012) Impacts of global warming on mountaineering: a classification of phenomena affecting the alpine trail network. Mountain Research and Development 32(1), 4-15 doi:10.1659/ MRD-JOURNAL-D-11-00036.1.

Rounce DR, King O, McCarthy M, Shean DE and Salerno F (2018) Quantifying debris thickness of debris-covered glaciers in the Everest region of Nepal through inversion of a subdebris melt model. Journal of Geophysical Research: Earth Surface 123(5), 1094-1115. doi:10.1029/ $2017 J$ J004395.

Salvatore MC and 7 others (2015) The state of Italian glaciers: a snapshot of the 2006-2007 hydrological period. Geografia. Fisica e Dinamica Quaternaria 38(2), 175-198. doi:10.4461/GFDQ.2015.38.16.

Schär C and 6 others (2004) The role of increasing temperature variability in European summer heatwaves. Nature 427(6972), 332-336. doi:10.1038/ nature 02300 .

Schmidli J, Schmutz C, Frei C, Wanner H and Schär C (2002) Mesoscale precipitation variability in the region of the European Alps during the 20th century. International Journal of Climatology 22, 1049-1074. doi:10. 1002/joc.769.

Schwarb MC, Daly C, Frey C and Schär C (2001) Mittlere jährliche Niederschlagshöhen im europäischen Alpenraum 1971-1990. Tafel 2.6. Hydrologische Atlas der Schweiz. Bern: Landeshydrologie und Geologie. https://hydrologischeratlas.ch/produkte/druckausgabe/niederschlag/tafel-2-6

Scotti R, Brardinoni F and Crosta GB (2014) Post-LIA glacier changes along a latitudinal transect in the Central Italian Alps. The Cryosphere, 8(6), 22352252. doi:10.5194/tc-8-2235-2014.

Shea JM and Immerzeel WW (2016) An assessment of basin-scale glaciological and hydrological sensitivities in the Hindu Kush-Himalaya. Annals of Glaciology 57(71), 308-318. doi:10.3189/2016AoG71A073.

Sorg A, Bolch T, Stoffel M, Solomina O and Beniston M (2012) Climate change impacts on glaciers and runoff in Tien Shan (Central Asia). Nature Climate Change 2(10), 725-731. doi:10.1038/nclimate1592.

Stocker-Waldhuber M, Fischer A, Helfricht K and Kuhn M (2019) Longterm records of glacier surface velocities in the Ötztal Alps (Austria). Earth System Science Data 11(2), 705-715. doi:10.5194/essd-11-705-2019.

Suter S, Laternser M, Haeberli W, Frauenfelder R and Hoelzle M (2001) Cold firn and ice of high-altitude glaciers in the Alps: measurements and distribution modelling. Journal of Glaciology 47(156), 85-96. doi:10.3189/ 172756501781832566.

Thibert E, Eckert N and Vincent C (2013) Climatic drivers of seasonal glacier mass balances: an analysis of 6 decades at Glacier de Sarennes (French Alps). Cryosphere 7(1), 47-66. doi:10.5194/tc-7-47-2013.

Vaughan DG and 13 others (2013) Observations: cryosphere. In Stocker TF, Qin D, Plattner G-K, Tignor M, Allen SK, Boschung J, Nauels A, Xia Y, Bex V and Midgley PM (eds), Climate Change 2013: The Physical Science Basis. Contribution of Working Group I to the Fifth Assessment Report of the Intergovernmental Panel on Climate Change. Cambridge, UK and New York, USA: Cambridge University Press, pp. 317-382.

Vergara W and 7 others (2007) Economic impacts of rapid glacier retreat in the Andes. Eos, Transactions American Geophysical Union 88(25), 261-264. doi:10.1029/2007EO250001.

Vincent C and 9 others (2017) Common climatic signal from glaciers in the European Alps over the last 50 years. Geophysical Research Letters 44(3), 1376-1383. doi:10.1002/2016GL072094.

Zanoner T and 6 others (2017) Little Ice Age mapping as a tool for identifying hazard in the paraglacial environment: the case study of Trentino (Eastern Italian Alps). Geomorphology 295, 551-562. doi:10.1016/j.geomorph.2017. 08.014 .

Zemp M and 38 others (2015) Historically unprecedented global glacier decline in the early 21 st century. Journal of Glaciology 61(228), 745-762. doi:10.3189/2015JoG15J017.

Zemp M and 14 others (2019) Global glacier mass changes and their contributions to sea-level rise from 1961 to 2016. Nature 568(7752), 382-386. doi:10.1038/s41586-019-1071-0. 